U.S. Department of Transportation Meifonel Highway

\title{
An Evaluation of the General Deterrent Effect of Vehicle Impoundment on Suspended and Revoked Drivers in California
}

\section{Final Report}




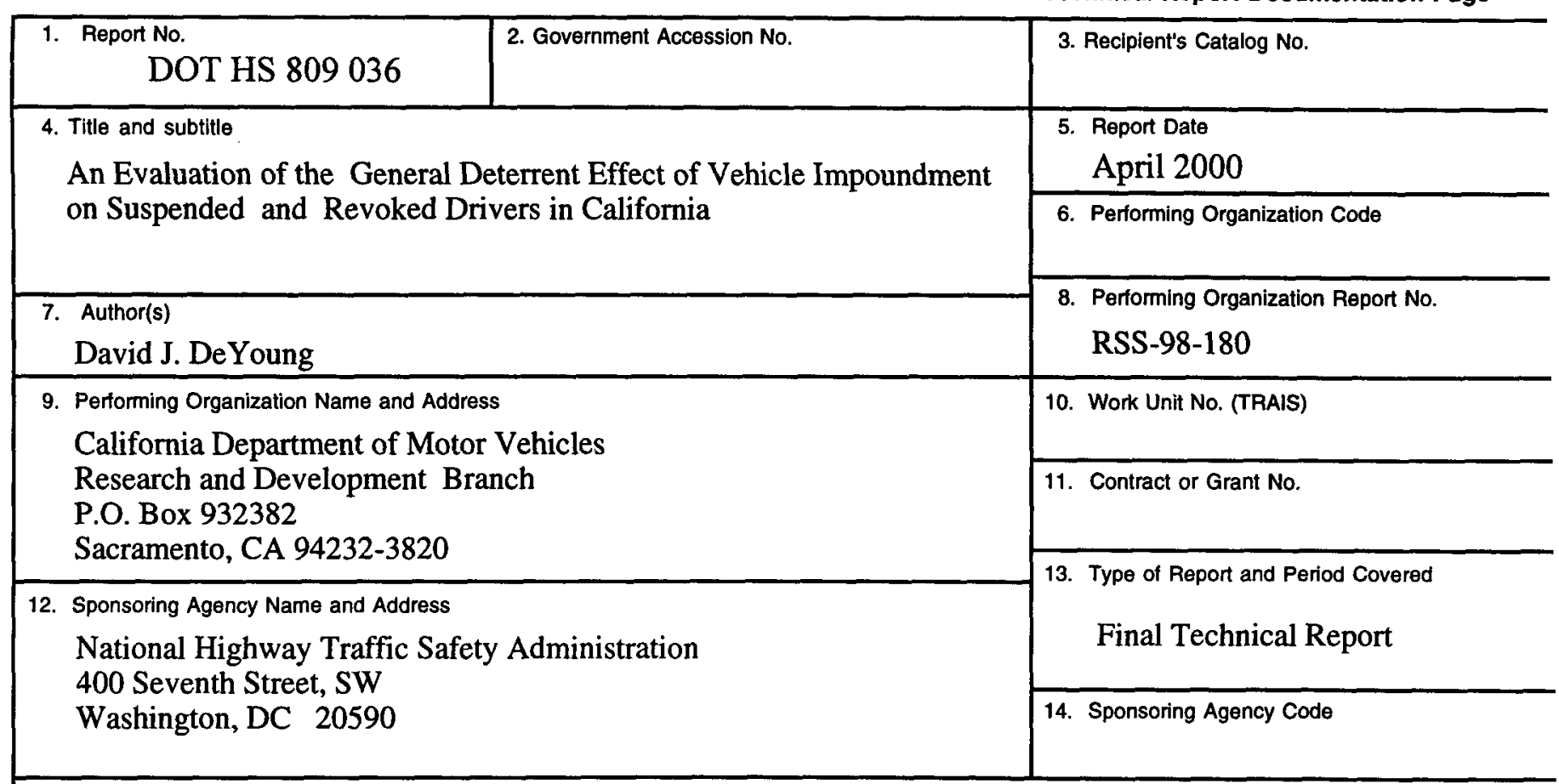

15. Supplementary Notes

Dr. Marvin Levy served as the Contracting Officer's Technical Representative.

16. Abstract

While license suspension/revocation have been shown to be effective, it is also known that most suspended/revoked (S/R) drivers violate their $S / R$ order and continue to drive, accruing traffic convictions and becoming involved in crashes. In an attempt to strengthen license actions and to better control S/R and unlicensed drivers, California enacted two laws effective January 1995 which provide for the impoundment/forfeiture of vehicles driven by $S / R$ and unlicensed drivers. The current study evaluates the general deterrent impact of vehicle impoundment on the crash rates for the general population of S/R drivers in California, regardless of whether they have been apprehended and punished for driving-while-suspended.

Crash rates for S/R drivers, as well as a control group of non-S/R drivers, were examined over a 5-year period consisting of 3 years prior to the implementation of vehicle impoundment/forfeiture and 2 years subsequent. Interrupted time series statistical models used to analyze the data showed that while there was a statistically significant drop in crashes for S/R drivers at the point at which the laws became effective, there was also a significant drop for control drivers, who shouldn't be affected by the laws since they are not $S / R$. Additional analyses which jointly estimated crashes for both $S / R$ and control groups revealed that the drop in crashes for $S / R$ drivers was no longer statistically significant once the crash rate for control drivers was statistically accounted for. Thus, this study failed to find compelling evidence of a general deterrent impact of vehicle impoundment/forfeiture in California.

17. Key Words
Vehicle impoundment/forfeiture,
suspended/revoked drivers, crash rates,
general deterrence

17. Key Words suspended/revoked drivers, crash rates, general deterrence

19. Security Classif. (of this report) Unclassified
20. Security Classif. (of this page)

Unclassified
18. Distribution Statement

Document Available to the Public

Through the National Technical

Information Service, Springfield VA

22161
21. No. of Pages

22. Price 


\section{PREFACE}

This report is the final product of an evaluation of the general deterrent effect of vehicle impoundment on suspended and revoked drivers in California. It is part of a larger project funded by the National Highway Traffic Safety Administration (NHTSA) which is being jointly undertaken by the California Department of Motor Vehicles (DMV) and the National Public Services Research Institute (NPSRI). The report was prepared by the Research and Development Branch of the DMV under the administrative direction of Raymond C. Peck, Chief. The opinions, findings and conclusions expressed in the report are those of the author and not necessarily those of NHTSA, NPSRI or the State of California. 


\section{ACKNOWLEDGMENTS}

This project received valuable assistance from a number of individuals, whom the author would like to recognize. Raymond C. Peck, Chief of the Research and Development Branch, provided general direction, and Clifford J. Helander, Research Manager I, supervised this study. Both individuals made valuable contributions to the content and methodology of the study, and the author appreciates their expertise and efforts.

The author would also like to thank Robert Hagge, Research Manager I, Richard McCleary, Professor of Social Ecology at the University of California, Irvine, and Bill Lattyak, of Scientific Computing Associates, Inc. for advice on the statistical modeling used in the project. Dr. Robert Voas reviewed the report and provided valuable feedback. Finally, Debbie McKenzie, Associate Governmental Program Analyst, prepared the tables and figures in the report, and coordinated its production. 


\section{EXECUTIVE SUMMARY}

\section{Background}

Injuries and fatalities resulting from motor vehicle crashes exact a huge human and economic cost and present a major public health problem for society. In 1996, motor vehicle crashes were the leading cause of unintentional injury deaths in the United States, and cost society more than $\$ 176$ billion (National Safety Council, 1997).

One recent approach to deal with the crash problem targets the vehicles driven by high-risk drivers, especially those whose licenses are suspended or revoked (S/R), or who have no license at all. These are logical groups to target. Although research has shown that license suspension/revocation are some of the most effective countermeasures currently in use to reduce crashes and traffic convictions among high-risk drivers (DeYoung, 1997; Peck, 1991; Peck \& Healey, 1995; Wells-Parker, Bangert-Drowns, McMillen \& Williams, 1995), they are only partially effective. Most $S / R$ drivers continue to drive while disqualified, albeit less often and more carefully (Hagen, McConnell \& Williams, 1980; van Oldenbeek \& Coppin, 1965), and while their crash and traffic conviction rates are lower than similar problem drivers whose driver licenses are not suspended or revoked, $S / R$ drivers still have fatal crash rates that are several times higher than those of the average driver (DeYoung, Peck \& Helander, 1997).

Vehicle-based programs can both strengthen license actions, by imposing more formidable penalties for driving while disqualified, and enhance traffic safety. These programs can take a number of forms, from the less intrusive ones of marking or confiscating vehicle license plates, to more direct and forceful ones, such as actually seizing and impounding, or forfeiting, vehicles.

Manitoba, Canada and Portland, Oregon are pioneers in the development and implementation of impoundment and forfeiture programs. Beginning in 1989, Manitoba implemented a law prescribing a 30-day period of vehicle impoundment for driving-while-suspended (DWS) offenders, and at about this same time Portland instituted a program that went a step beyond Manitoba's by providing for the civil forfeiture of vehicles. A study of Manitoba's programs, which must be regarded as providing only suggestive evidence of the efficacy of impoundment due to the lack of rigorous research design or statistical controls, found that the program was 
associated with reductions in both DWS recidivism and traffic convictions (Beirness, Simpson \& Mayhew, 1997). A better controlled study of Portland's program showed that it reduced recidivism by about $50 \%$ (Crosby, 1995).

More recently, Ohio initiated vehicle impoundment and vehicle immobilization programs targeting $S / R$ and multiple driving-under-the-influence (DUI) offenders. Evaluations of impoundment (Voas, Tippetts \& Taylor, 1998) and immobilization (Voas, Tippetts \& Taylor, 1997) found that both of these countermeasures were effective in reducing subsequent DWS and DUI offenses.

\section{Vehicle Impoundment in California}

During the 1994 legislative session, the California Legislature passed two bills prescribing vehicle impoundment (Senate Bill [SB] 1758) and vehicle forfeiture (Assembly Bill [AB] 3148), effective January 1995. SB 1758 authorizes peace officers to seize and impound for 30 days vehicles driven by $S / R$ and unlicensed drivers, while $A B 3148$ goes a step further by authorizing the forfeiture of vehicles driven by $S / R$ and unlicensed drivers who are the registered owners of the vehicles and who have a prior conviction for DWS or driving-while-unlicensed (DWU).

The impoundment and forfeiture laws adopted in California are the first attempt to implement these countermeasures on a large scale; the jurisdictions which have used impoundment/forfeiture in the past are relatively modest in size by comparison. In California, approximately one million drivers are $S / R$ at any given time, and it is estimated that there are about one million additional drivers who are unlicensed. Thus, a study of impoundment and forfeiture in California can add to the small but growing body of research on the effectiveness of vehicle impoundment and forfeiture and, importantly, reveal whether these measures can be successfully utilized on a large scale.

The present study is part of a larger research project to evaluate vehicle impoundment and forfeiture which was funded by the National Highway Traffic Safety Administration (NHTSA), and undertaken jointly by the California Department of Motor Vehicles (DMV) and a private research firm, the National Public Services Research Institute (NPSRI). Another component of this study, completed at the end of 1997, evaluated the effects of California's impoundment law on the rates of 1-year subsequent crashes, DWS convictions and total traffic convictions for offenders whose vehicles were actually impounded (DeYoung, 
1997a). This study found that vehicle impoundment was associated with significant reductions in all three crash and conviction measures, and that it appeared to be even more effective with repeat DWS/DWU offenders than with first offenders.

However, an important question remains unanswered. While impoundment appears to be effective with offenders who actually experience it (i.e., specific deterrence), does the threat of impounding/forfeiting vehicles deter $S / R$ and unlicensed drivers from driving and becoming involved in crashes, regardless of whether they have been caught and punished (i.e., general deterrence)? In theory, impoundment and forfeiture will more likely wield a general deterrent impact if $S / R$ and unlicensed drivers view this punishment as certain, swift and severe (Ross, 1992). Because the laws are applied administratively, they are fairly certain and swift, relative to most offenses that are adjudicated by the courts, and the loss of a vehicle may be regarded by most people as a severe punishment. Thus, the structure of the vehicle impoundment and forfeiture laws in California provides the opportunity for them to exert a general deterrent impact. To ascertain whether they in fact did so is the purpose of the present study.

\section{Research Methods}

While the vehicle impoundment and forfeiture laws apply to both $S / R$ and unlicensed drivers, there are serious problems in identifying and studying unlicensed drivers, so the current study is limited to an examination of the effects of impoundment and forfeiture on $S / R$ drivers. All drivers in California who were $S / R$ between January 1992 and January 1997 were identified using DMV's driver record database, and then demographic and driving history data for them were extracted and organized into 65 separate 28-day time periods. In addition, these same data were extracted and organized for a random sample of California drivers who were not $S / R$. This latter group, who is not subject to impoundment/forfeiture and thus should not be influenced by the new laws, was used as a baseline (or control group) to compare with $S / R$ drivers.

Because it was not feasible to randomly assign drivers to $S / R$ or control conditions, the study used a quasi-experimental design to examine the crash rates of $S / R$ drivers over the course of the 5 year study period. In essence, the design, an interrupted time series, compares the crash rates of $S / R$ drivers after the vehicle impoundment/forfeiture laws became effective to the rates of $S / R$ drivers before the laws were implemented. By using a large number of measurement points, the 
design provides for a fairly convincing assessment of whether the intervention, the new vehicle impoundment and forfeiture laws, affected the crash rates of $S / R$ drivers. The control group of non-S/R drivers provides a measure of the effects of other historical events occurring at the same time as impoundment/forfeiture, and thus provides additional assurance that any changes observed in the crash rate for $S / R$ drivers is likely due to impoundment/forfeiture, rather than these other extraneous factors.

\section{Results and Discussion}

Several sets of analyses were conducted in order to assess whether vehicle impoundment and forfeiture exerted a general deterrent effect on $S / R$ drivers in California. Analyses were first performed examining just the crash rates of $S / R$ drivers, and then these analyses were repeated looking at the rates for only control drivers. The final sets of analyses examined the rates of crashes for both $S / R$ and control drivers jointly.

\section{$\underline{S / R}$ crashes}

A crash rate series was developed for $S / R$ drivers by dividing the number of crashes in each time period by the number of $S / R$ drivers in that time period. This crash rate series is shown in Figure 1. 


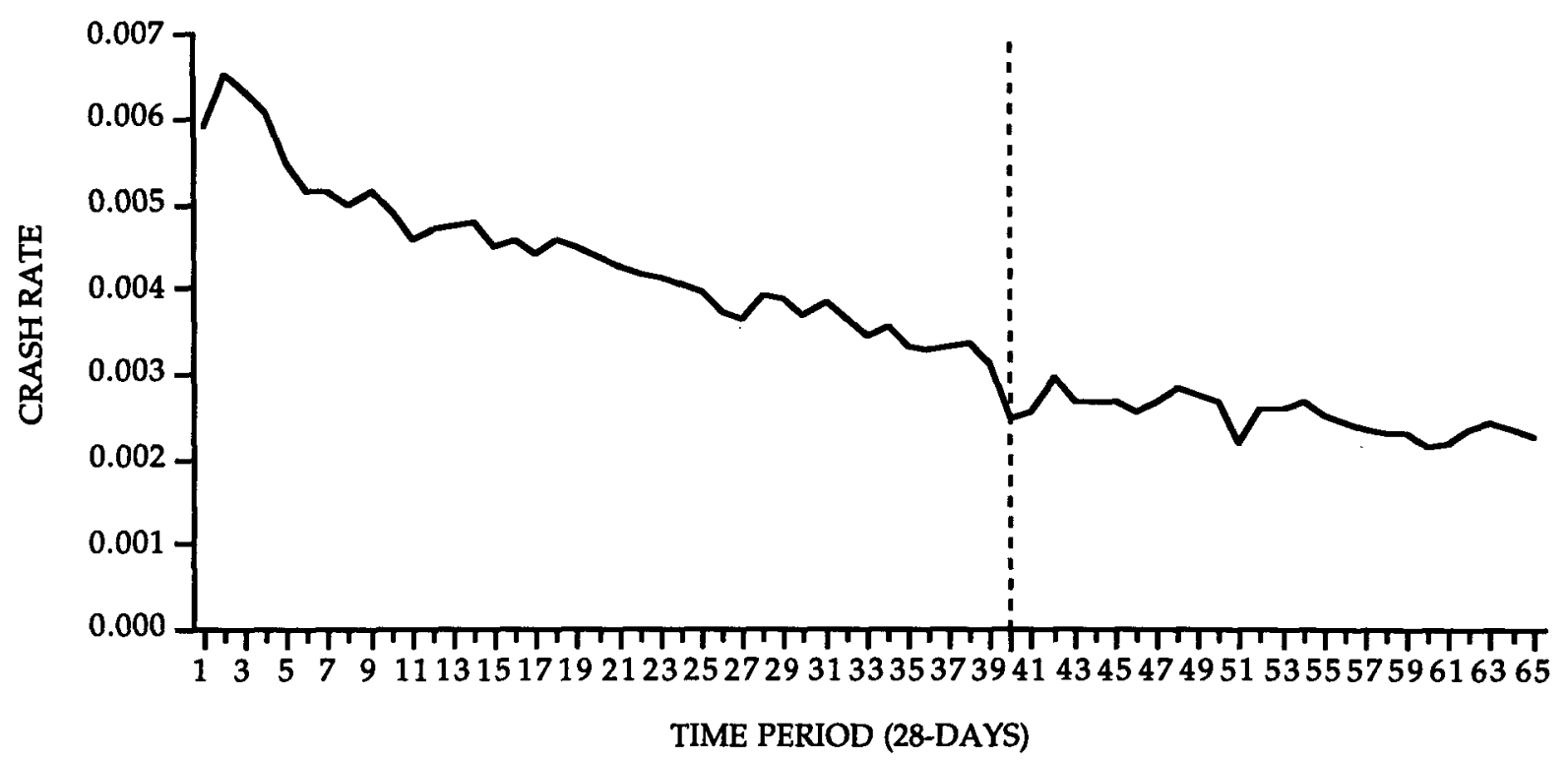

Figure 1. Crash rates for $S / R$ drivers.

The most noticeable feature of Figure 1 is the strong downward trend in the $S / R$ crash rate over the study period. A vertical line has been inserted at time period 40, the point at which the vehicle impoundment and forfeiture laws became effective. It can be seen that the crash rate falls abruptly at this point, suggesting the possibility that these new laws influenced crashes for $S / R$ drivers. This is confirmed by the statistical analyses (ARIMA intervention models), which found that this abrupt drop in crashes, while only temporary in duration, was statistically significant and amounted to a decline of $13.6 \%$ in the crash rate. At this early point in the analyses, it appears that there may be a significant general deterrent effect of vehicle impoundment/forfeiture on S/R drivers in California.

\section{Control crashes}

While there appears to be a decline in crashes for $S / R$ drivers that occurred at the same time that the vehicle impoundment/forfeiture laws became effective, there is a possibility that some other extraneous forces contemporaneous with the laws may have been responsible for some or all of this drop in crashes; this is where it becomes important to examine crashes for the non-S/R, or control, sample. A crash rate was developed for control drivers, and the results are portrayed in Figure 2. 


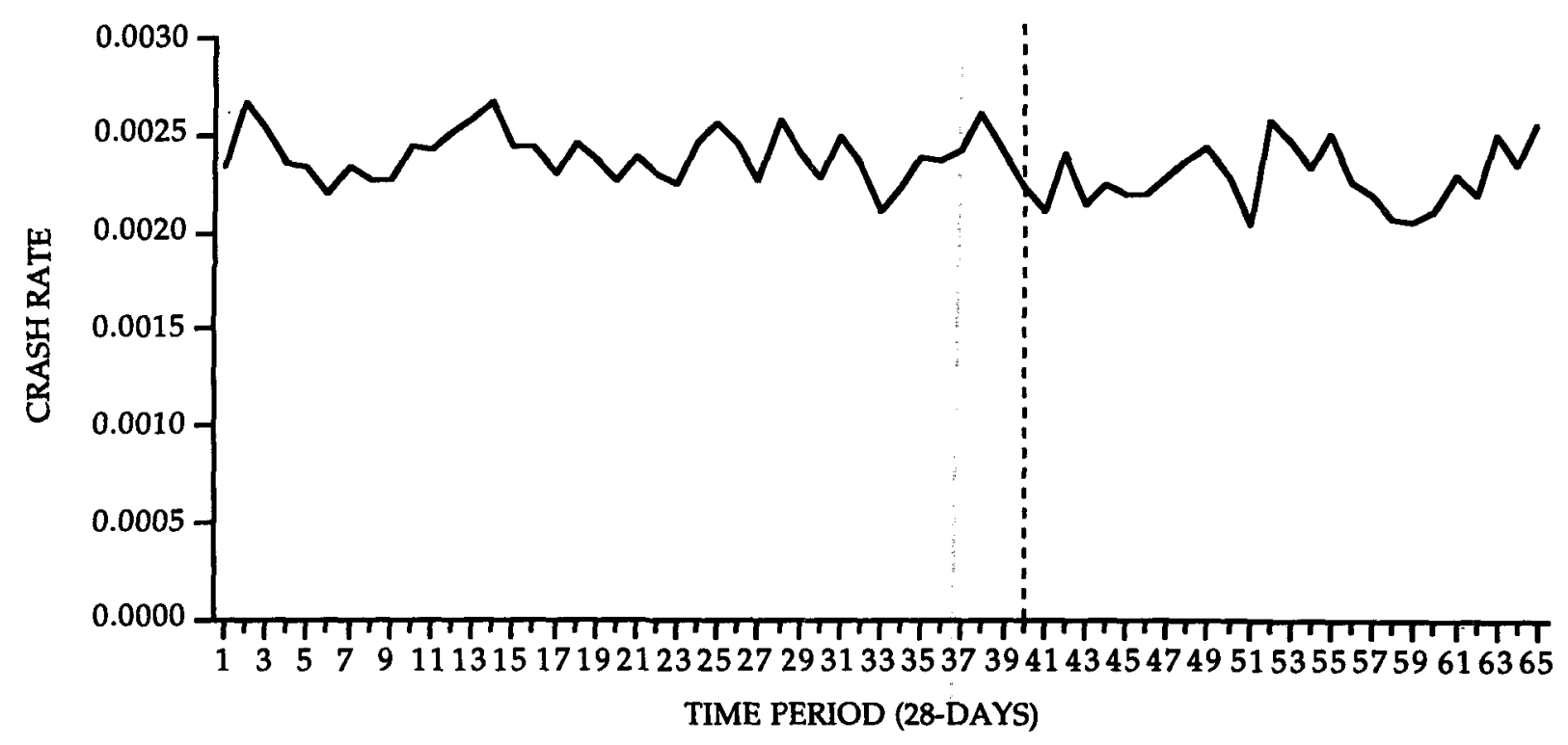

Figure 2. Crash rates for control drivers.

It is interesting to note that there is no noticeable upward or downward trend in the control crash series, as there was with the $S / R$ series. A vertical line has been inserted at time period 40 , the point of impoundment and forfeiture, and it can be seen that there is an abrupt drop in crashes for control drivers at this point. The statistical analyses revealed that this drop, like the one for $S / R$ drivers, was only temporary but was statistically significant, amounting to a decline of $8.3 \%$. Because control drivers are not $S / R$ they are not subject to impoundment or forfeiture, and so we would not expect them to be influenced by the implementation of these countermeasures. Yet their crash rate dips at the same time the laws became effective, suggesting that other extraneous forces were responsible for a drop in crashes for all drivers, $S / R$ or not.

\section{$\underline{S / R}$ and control joint analyses}

Two additional sets of analyses were performed in an attempt to clarify the results of the separate analyses conducted on the $S / R$ and control crash data. These two sets, while different in methods and complexities, share a similar important feature; they both estimate the effects of impoundment/forfeiture for $S / R$ drivers, while statistically accounting for the crash rate of control drivers. 
Preliminary analyses revealed that there was a significant contemporaneous relationship between $S / R$ and control crashes. That is, both crash series share a similar pattern of variation over the course of the study period. These results indicate that it may be useful to incorporate the crash rate of control drivers in the model developed to estimate the effects of impoundment/forfeiture on $S / R$ drivers.

The results of both sets of analyses agreed with one another, and showed that the statistically significant abrupt temporary drop in crashes for $S / R$ drivers that occurred when impoundment/forfeiture became effective became only marginally significant once the crash rate for control drivers was statistically accounted for. These results are not surprising in light of the results of the separate analyses of $S / R$ and control crashes, which showed that the crash rates dropped significantly for both groups. Note, however, that the decline in crash rates is larger for $S / R$ drivers (13.6\%) than for control drivers (8.3\%); while some extraneous factor appears responsible for the majority of the drop in crashes for $S / R$ drivers, it is still possible that there was a small general deterrent impact of vehicle impoundment/forfeiture over-and-above that due to other forces. But, even if this is true, the effect is so small and dissipates so quickly that it would have little practical significance.

\section{Conclusion}

This study did not find compelling evidence of a general deterrent impact of vehicle impoundment and forfeiture on crashes for one of the main groups it targets, $S / R$ drivers. While crashes for $S / R$ drivers did drop temporarily at the same time the laws became effective, crashes also dropped for control drivers, who are not $S / R$ and who thus would not be expected to be influenced by the laws. This suggests that some other extraneous force was largely responsible for a drop in crashes for all drivers, $S / R$ or not.

It is not completely clear why this study failed to find a general deterrent impact of the laws, especially given the strong positive effects of impoundment found in the specific deterrent study. It is possible that there was insufficient advance publicity informing $S / R$ and unlicensed drivers that their vehicles could be impounded or forfeited if they drove without a valid license. If so, many $S / R$ and unlicensed 
drivers would be unaware of the new laws, and thus would not be influenced by them.

Considered together, the results of both the specific and general deterrent studies seem to be telling us that if you seize and impound the vehicle of someone DWS/DWU, that this will have a significant impact in reducing their driving risk (specific deterrence), but that the threat of impounding and forfeiting vehicles does not change the behavior of the general population of $S / R$ drivers, who may or may not have been apprehended and punished (general deterrence).

What policy recommendations arise from this study? While there is little evidence of a general deterrent impact of vehicle impoundment/forfeiture, the strong evidence of a substantial specific deterrent impact found in earlier studies (Beirness, Simpson \& Mayhew, 1997; Crosby, 1995; DeYoung, 1997a; Voas, Tippetts \& Taylor, 1997; Voas, Tippetts \& Taylor, 1998) provides a compelling argument in support of vehicle impoundment. The longer that these measures are used, and the more consistently and widely they are applied, the more likely it is that they will eventually exert a general deterrent impact as well as a specific deterrent one. 


\section{TABLE OF CONTENTS}

$\underline{\text { PAGE }}$

PREFACE i

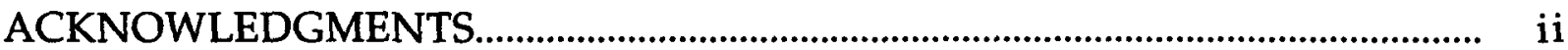

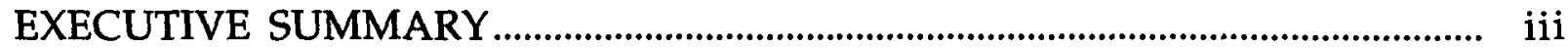

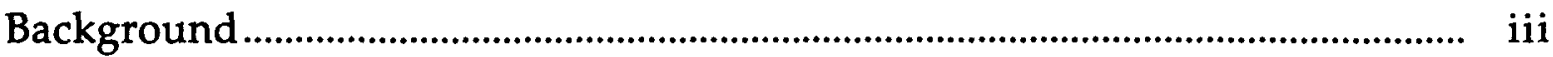

Vehicle Impoundment in California.................................................................... iv

Research Methods ................................................................................................... v

Results and Discussion................................................................................... vi

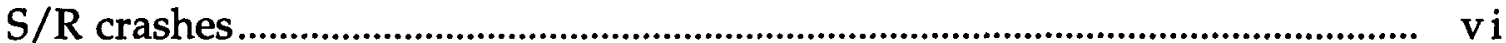

Control crashes..................................................................................................... vii

$\mathrm{S} / \mathrm{R}$ and control joint analyses.............................................................................. viii

Conclusions ............................................................................................................. ix

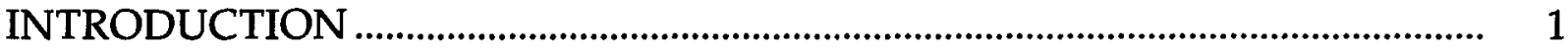

Vehicle-based Programs............................................................................................... 2

Vehicle Impoundment in California....................................................................... 4

Current Study .................................................................................................................. 5

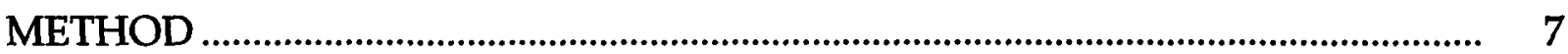

Subject Selection ............................................................................................... 7

Data Collection.................................................................................................... 8

Evaluation Design and Statistical Analyses............................................................... 11

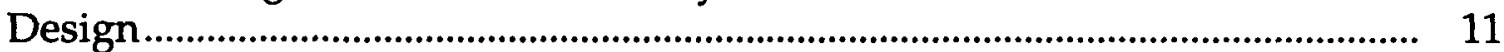

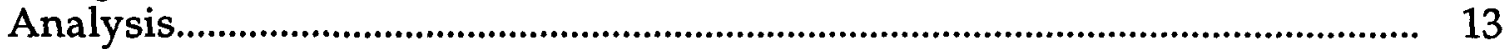

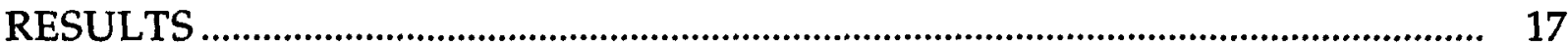

Univariate Intervention Analysis..................................................................... 17

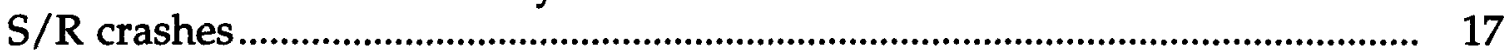

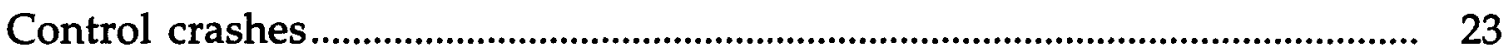

Intervention and Transfer Function Analyses: S/R Crashes............................. 27

Simultaneous Transfer Function Analyses ................................................................ 29 


\section{TABLE OF CONTENTS (Continued)}

$\underline{\text { PAGE }}$

DISCUSSION 33

Results and Analyses.......................................................................................... 34

Conclusion and Recommendations............................................................. 36

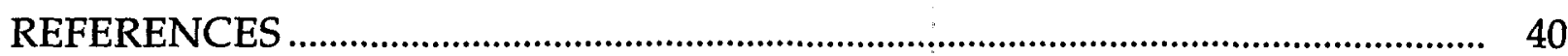

\section{LIST OF TABLES}

\section{NUMBER}

PAGE

1 The Effects of an Abrupt Temporary Intervention of Vehicle Impoundment on Crash Rates for S/R Drivers

2 The Effects of an Abrupt Temporary Intervention of Vehicle Impoundment on Crash Rates for Control Drivers...............................

3 Abrupt Temporary Intervention Effects on S/R Crashes Using Control Crashes as a Transfer Function

4 STF Analyses to Jointly Estimate Abrupt Temporary Intervention Effects for Both $S / R$ and Control Crashes

\section{LIST OF FIGURES}

1 Crash rates for S/R drivers.......................................................................... 18

2 Differenced crash rates for $S / R$ drivers .......................................................... 21

3 Crash rates for control drivers............................................................................... 24 


\section{INTRODUCTION}

Injuries and fatalities resulting from motor vehicle crashes exact a huge human and economic cost and present a major public health problem for society. The National Safety Council (NSC) reports that in the United States in 1996, motor vehicle fatalities were the leading cause of unintentional injury deaths, and were the fifth leading cause of death overall, exceeded only by such chronic diseases as heart disease and cancer (National Safety Council, 1997). The NSC estimates that motor vehicle crashes cost the nation more than \$176 billion in 1996.

There have been many attempts over the years to reduce motor vehicle crashes and enhance traffic safety, and these have met with some success. For example, the number of deaths per 100 million miles traveled reached an all-time low in California in 1996 (California Highway Patrol, 1996), and California alcoholinvolved traffic fatalities have declined by more than half since 1987 (Tashima \& Helander, 1998). Despite this progress, the traffic crash problem remains formidable, and traffic safety professionals and advocates have been searching for new countermeasures to further attenuate the problem.

One relatively recent traffic safety approach targets the vehicles driven by high-risk drivers. These countermeasures are usually aimed at drivers whose licenses have been suspended or revoked (S/R), or those who have no license at all. These are logical groups to target. License suspension and revocation, for example, have been shown to be among the most effective countermeasures available for dealing with alcohol-involved and other problem drivers (DeYoung, 1997; Peck, 1991; Peck \& Healey, 1995; Wells-Parker, Bangert-Drowns, McMillen \& Williams, 1995). Yet license actions are only partially effective, and do not make these drivers safe. Research has shown that most $S / R$ drivers will continue to drive, albeit less often and more carefully, (Hagen, McConnell \& Williams, 1980; van Oldenbeek \& Coppin, 1965), and while their crash and traffic conviction rates are lower than similar drivers whose driver licenses are not suspended, both $S / R$ and unlicensed drivers have fatal crash rates that are several times higher than those of the average driver (DeYoung, Peck \& Helander, 1997). In short, while license suspension/revocation are effective, there is ample room for improvement. 
Vehicle-based programs represent one avenue to potentially strengthen license actions and thus better control problem drivers, and to enhance traffic safety. Driving without a valid license occurs largely because the laws are difficult to enforce-it is essentially an "invisible" offense-and because the punishment is not severe and is applied inconsistently (DeYoung, 1990). Vehicle-based sanctions may increase compliance with license suspension/revocation orders because they are usually administrative in nature, and thus are more likely to be applied quickly and widely, and because the threat of seizing a vehicle may be severe enough to deter some potential offenders from violating. In addition to deterring $S / R$ and unlicensed drivers from driving, vehicle-based sanctions may directly prevent those drivers that are apprehended driving while $S / R$ (DWS) or driving while unlicensed (DWU) from future transgressions through the mechanism of incapacitation. During the period of time that they don't have access to their vehicle, such offenders will find it more difficult to drive and thus commit new violations. Given their risk level, this may ultimately enhance traffic safety.

\section{Vehicle-Based Programs}

Vehicle-based sanctions can take a number of forms. One of the least intrusive is to mark the license plates of offenders' vehicles in some way, or to remove the plates altogether. This has the effect of making the invisible offenses of DWS or DWU more visible, and thus is likely to deter $S / R$ and unlicensed drivers from driving in the first place. It also is likely to increase the probability that law enforcement will detect $S / R$ and unlicensed drivers, if they do drive. A more forceful approach is to seize and either immobilize or impound the vehicle of offenders caught DWS/DWU.

Minnesota was one of the first jurisdictions to develop and implement a sanction targeting the vehicles of problem drivers. The state enacted a law, effective January 1988 , requiring the courts to confiscate and destroy the license plates of vehicles registered to repeat driving-under-the-influence (DUI) offenders. However, as time went by it became clear that the courts were not implementing the provisions of the law, so it was amended to make it administrative in nature, allowing peace officers to remove the plates. Rodgers (1994) evaluated the law, and found that it was used more consistently once it became administrative, and that it reduced recidivism significantly among repeat DUI offenders. 
The state of Washington implemented a license plate sticker law targeting problem drivers. Their law, which became effective at about the same time as Minnesota's, allowed peace officers to mark the plates of vehicles driven by $S / R$ drivers by placing a "zebra" tag over the annual registration sticker on the plate. A year-and-a-half later, Oregon followed suit, implementing a very similar license plate tag program.

Voas and Tippetts (1995) evaluated both the general and specific deterrent effects of the license plate tag programs in Washington and Oregon. General deterrence refers to how people's perceptions of the consequences for violating a law affect their behavior regarding it. If people believe that the consequences for violating the law are swift, certain and severe, they will more likely be deterred from offending; a great strength of general deterrence is that it acts on all people who are in a position to violate the law (Ross, 1992). In the case of Washington and Oregon's license plate tag laws, if there was a general deterrent effect of the laws, then the overall rate of DWS crashes/convictions would be lower for all $S / R$ drivers once the law was enacted. Voas and Tippetts found that there was a significant general deterrent impact of the laws in Oregon, but that no impact was evident in Washington.

Specific deterrence posits that offenders who are apprehended and punished for violating a law will be less likely to violate again in the future. Studies measuring recidivism are assessing whether a specific deterrent effect has occurred. Voas and Tippetts found that drivers whose plates were tagged in Oregon had a lower rate of subsequent crashes than drivers whose plates were not tagged. However, as with the general deterrent analysis, there was no specific deterrent effect for Washington drivers.

While Minnesota, Washington and Oregon were experimenting with tagging or confiscating the license plates of problem drivers, Manitoba Canada was exploring whether the more forceful and direct approach of seizing and impounding (for 30 days) vehicles driven by high-risk drivers could have salutary effects on traffic safety in the region. Beirness, Simpson and Mayhew (1997) evaluated the specific deterrent effect of Manitoba's program, and found that it was associated with significant reductions in DWS recidivism and traffic convictions, although their findings should be regarded as suggestive rather than definitive due to the lack of a rigorous evaluation design or strong statistical controls. 
Portland, Oregon was a pioneer in developing and implementing an administrative vehicle impoundment/forfeiture program in the United States. Their program, initiated in 1989, went a step beyond Manitoba's by providing for the civil forfeiture of an impounded vehicle. Crosby (1995) evaluated Portland's forfeiture program and found that it reduced the recidivism rate of drivers whose vehicles were seized to about half that of drivers whose vehicles were not taken. Interestingly, having a vehicle forfeited did not affect the recidivism rate any more than if it was simply seized and held for a relatively brief period.

More recently, Ohio implemented an impoundment and immobilization program targeting $S / R$ and multiple DUI offenders. Evaluation studies of the implementation of this law in two Ohio counties have been completed recently. The first study (Voas, Tippetts \& Taylor, 1997) examined Franklin County's program, where peace officers impound vehicles for a brief period pending a court hearing, and then if ordered by the court, tow vehicles to offenders' homes and immobilize them by installing a "club" device on the steering wheel. The second study (Voas, Tippetts \& Taylor, 1998) evaluated the program in Hamilton County, where vehicles were simply impounded. Both programs were shown to be effective in reducing the rates of DUI and DWS offenses, presumably through incapacitation while the vehicle was actually impounded/immobilized, and in deterring persons from reoffending once the vehicle was released.

\section{Vehicle Impoundment in California}

The first concerted effort in California to impound the vehicles of problem drivers was undertaken by the Santa Rosa Police Department in late 1993. Their program, named the STOP program (Santa Rosa Traffic Offender Program), garnered substantial media attention and has become a model for more than a dozen such programs throughout the state.

This visibility came to the attention of the California Legislature, which examined the STOP program as well as other similar programs throughout the country, and combined the experiences and procedures of these programs with recommendations for dealing with the $S / R$ and unlicensed driver problem made by the California Department of Motor Vehicles (DeYoung, 1990), in enacting two bills during the 
1994 legislative session. The first, Senate Bill (SB) 1758, is administrative in nature. It allows peace officers, once they have determined that a driver is $S / R$ or unlicensed, to cite/arrest the driver for DWS/DWU and to arrange for the vehicle to be towed to an impound lot. The registered owner of the vehicle can reclaim it at the end of the impound period (generally 30 days) by showing a valid driver license and by paying all towing and impoundment costs, plus an administrative fee charged by the impounding agency. Vehicles that are unclaimed are auctioned.

The second bill, Assembly Bill (AB) 3148, prescribes tougher penalties than its Senate counterpart by providing for the forfeiture of vehicles driven by $S / R$ and unlicensed drivers, if they are the registered owners of the vehicles and if they have a prior conviction for DWS/DWU. Under certain conditions, a vehicle otherwise subject to forfeiture may be released to a family member who has a community property interest in the vehicle. Forfeiture proceedings are initiated by the district attorney having jurisdiction in the area.

SB 1758 and AB 3148 specified an implementation date of January 1995, although many jurisdictions did not begin impounding/forfeiting vehicles immediately, due to resource constraints and procedural difficulties associated with developing and implementing these programs. Although subsequent "clean-up" legislation was enacted, the major components of both laws remain intact. California's impoundment/forfeiture laws are of particular interest because they are the first to attempt such sanctions on a large scale; there are about one million drivers in the state who are $S / R$ at any given time, and another estimated one million who are unlicensed. Thus, there are hundreds of thousands of vehicles that could potentially be seized and impounded/forfeited each year. These large numbers pose a substantial problem, but also the potential for a significant improvement in traffic safety in the state.

\section{Current Study}

The current study is part of a joint project funded by the National Highway Traffic Safety Administration (NHTSA) and undertaken by the California Department of Motor Vehicles (DMV) and the National Public Services Research Institute. The California DMV has primary responsibility for two separate studies, one evaluating 
the specific deterrent impact of impoundment/forfeiture in the state, and the other examining the general deterrent impact of these laws.

The specific deterrent study was completed at the end of 1997 (DeYoung, 1997a). This study compared the 1-year subsequent driving records of $S / R$ and unlicensed drivers whose vehicles were impounded, to the driving records of a similar group of such drivers whose vehicles were not impounded, and found that impounded drivers with no prior DWS/DWU convictions had significantly fewer subsequent DWS/DWU convictions (24\%), total traffic convictions (18\%), and crashes $(25 \%)$ than their counterparts who did not lose their vehicles. Importantly, these significant effects were even more pronounced for repeat offenders (that is, offenders with prior DWS/DWU convictions); repeat offenders in the impound group had $34 \%$ fewer DWS/DWU convictions, $22 \%$ fewer traffic convictions and $38 \%$ fewer crashes than repeat offenders whose vehicles were not impounded.

The specific deterrent study confirmed the positive results of impoundment found by other researchers, and also showed that such a countermeasure could successfully be carried out on a large scale. However, one important question remains. Impoundment appears to reduce crashes and traffic convictions for those $S / R$ and unlicensed drivers who are apprehended and punished, but does the threat of impounding/forfeiting vehicles deter the general population of $S / R$ and unlicensed drivers from driving and accruing traffic convictions and becoming involved in crashes, regardless of whether they have been caught and punished? That is, does impoundment/forfeiture have a general deterrent impact as well as a specific one? That is the central question of the current study, and the subject of this paper. 


\section{METHOD}

\section{Subject Selection}

In order to conduct a general deterrent analysis of vehicle impoundment/forfeiture in California, it was necessary to identify and select all $S / R$ drivers in the state. Ideally, it would have been desirable to also identify and select all unlicensed drivers in California, since they are also subject to vehicle impoundment and forfeiture. However, it is very difficult to identify unlicensed drivers. They are essentially "invisible" until they are apprehended for committing a traffic offense, or become involved in a crash. In these situations, some unknown proportion of them become known to the DMV when a court reports to the department that they were convicted of a traffic offense, or the department learns that they were involved in a crash; however, even this subgroup of unlicensed drivers is difficult to study because their driving records are unreliable. Unfortunately, there is no feasible way to reliably include unlicensed drivers in a study of this type, and so the present study is limited to examining the general deterrent effect of impoundment/forfeiture on $S / R$ drivers.

The DMV driver record database was used to identify and select $S / R$ drivers for the study. This database contains demographic, driving history, and certain legal and departmental action information on all drivers in California who have applied for either a driver license or an identification card. Drivers were identified through file passes of the entire driver record database. During these procedures, each of the more than 20 million records in the database were examined, and if a driver had been S/R at any time during the study period of January 1992 through December 1996, identifying information on them was written to an output computer file. This initial step yielded a sample of more than 2.5 million drivers.

Once the sample had been identified, various computer extraction programs were utilized to obtain demographic and driving history data during the time period of interest for the sample subjects. Also, during this stage information became available to identify subjects who should be excluded from the study. Drivers were excluded if their driver licenses were prefixed with an " $X$." These are termed " $X$ records" and are created when the DMV receives an abstract of conviction from a court and is unable to locate the offender in the driver record database. In such cases 
the driver is assigned a number in the database which is prefixed with an $X$, and information on the conviction is entered for the subject under this number. Drivers with $\mathrm{X}$ records were dropped from the sample because data on their driving history is unreliable.

The design of the general deterrent study also included a comparison (or control) group, which was used as a benchmark when assessing the driving behavior of $S / R$ drivers. The control group for this study was comprised of a $1 \%$ random sample of all California drivers. The Research and Development Branch at DMV maintains an ongoing computer file of such drivers, and this file was used to identify control subjects. This first step yielded approximately 370,000 control drivers.

Once the control drivers were selected and identifying information on them was written to a computer output file, the same data extraction procedures used to select demographic and driving history data for $S / R$ drivers were employed to obtain this information for control drivers. As with $S / R$ drivers, control drivers whose driver license number was prefixed with an $\mathrm{X}$ were excluded from the study, because data on their driving history is unreliable.

\section{Data Collection}

After collecting the data for $S / R$ and control drivers from DMV's driver record database, it was necessary to organize the data into 28-day time periods. The general deterrent study design involves an analysis of changes in patterns of driving behavior over time. Organizing the data into 28-day time periods avoids calendar effects that can occur in monthly data when, for instance, there are more weekends or holidays in some months than in others. This can create changes in the patterns of the data over time that have nothing to do with the phenomenon under study, but rather are simply due to artifacts created by the organization of the data. Structuring the data into 28-day time periods avoids this potential bias.

The 5-year study time period, January 1992 through December 1996, is comprised of 65 discrete 28-day time periods. Computer manipulation and extraction programs were used to organize data for $S / R$ and control drivers into 13 files of 5 time periods each, covering all 65 time periods. The next step involved examining only $S / R$ drivers; the SPSS statistical computer package was used to look at each time period 
separately, and then to select only drivers who were $S / R$ during that time period and count their numbers of motor vehicle crashes. This procedure needed to be performed because, while the $S / R$ datafiles consisted of drivers who were $S / R$ at some point during the study, most were not $S / R$ for the entire study period.

These same procedures were used for control drivers, except that for these subjects SPSS was used to select only drivers who were not $S / R$ during each time period, and to count their numbers of crashes. This process yielded two groups of drivers for each time period, one consisting of drivers who were $S / R$, the other drivers who were not $S / R$. It is important to point out that these groups are dynamic; subjects can move in and out of their respective groups over the course of the study, and the sample sizes of the groups change somewhat from time period to time period. While the control group ranged in size from about 330,000 to 332,000 , the sample sizes for the $S / R$ group ranged from approximately 500,000 to more than $1,100,000$ (the sample sizes for the $S / R$ group are smaller during the initial study periods in part because the initial sampling process selected all drivers who were $S / R$ at some point during the 5 year study period--since many of the suspensions/revocations are lengthy and last through much of the study period, there is an effect of 'adding' those drivers to the $S / R$ group during succeeding time periods whose $S / R$ action began later during the study period).

The outcome measure used to assess the general deterrent impact of vehicle impoundment in California is motor vehicle crashes, which as explained earlier was obtained from DMV's driver record database. However, there is some potential bias in the crash data due to the study design and the way in which data were collected. Crash data is reported to DMV by the California Highway Patrol (CHP) and by drivers themselves, but there is some time that elapses between the crash and the posting of these data to DMV's database. Because data were extracted at one point in time, and because the study covers a 5 year time period, drivers early in the study period will have had substantially more time for crash data to be posted to their records than will drivers in the later time periods. This could have the effect of undercounting crashes for drivers later in the study period, making them appear to be safer drivers than they really are. Given that the study compares crash rates for drivers after the vehicle impoundment/forfeiture laws were implemented to the rates of drivers before the law, this undercounting of crashes in the later time periods could masquerade as a salutary effect of the law. 
In order to check the seriousness of this potential bias, data were collected on crash dates and their dates of posting to DMV's driver record database. Using these two variables, a new variable consisting of the number of months between crash and update to DMV's database was created. Next, for time periods throughout the study, frequencies were calculated of the percentage of crashes that were updated within 10 months. The minimum update time lag is for drivers in the 65th time period, who have about 15 months from their time period to the point at which data were collected for all drivers. If most crashes are updated within 10 months, and there is no change in this throughout the study period, then the differences in the amount of time drivers throughout the study have for crashes to be updated to their records will not pose a serious problem. And, in fact, this is what the data on crash update time showed. Between $97.5 \%$ and $99.5 \%$ of crashes were updated within 10 months, and this variation did not show a systematic pattern over the course of the study period. Thus, the differences in the amount of time available to update crash data for drivers at different times in the study do not pose a significant bias.

Once the number of drivers and crashes were calculated for each time period, the data were plotted to check for accuracy. The data for both control and S/R drivers showed a dramatic drop in crashes at time periods 12 and 13 , corresponding to November and December of 1992. After some investigation, it was discovered that some of the CHP crash data for these months was lost by DMV, and that these data were unrecoverable. At this point, a number of options were available to deal with the missing data. The first 13 time periods could simply be dropped from the study, and the analysis conducted on the remaining 52 time periods. While this option avoids the messiness inherent in estimating missing data, it shortens an already somewhat brief data series, which would reduce the statistical power of the study.

The avenue taken in this study was to use a rather complex missing data estimation procedure available in the SCA statistical software package. This estimation procedure involves an iterative approach where a model of the time series is developed, residuals computed, and then the residuals checked for outliers. If an outlier is discovered, its effects are removed from the residuals, and then the whole process repeats until no new outliers are detected. The estimation procedure also adjusts the observed series for outlier effects, providing estimates of missing data. Detailed information on this procedure, known as OESTIM, can be found in Liu and Hudak (1992). OESTIM was used to compute missing values for time periods 12 and 13 for both the $S / R$ and control crash series. 


\section{Evaluation Design and Statistical Analyses}

\section{Design}

The question addressed by this study is whether the threat of impounding/forfeiting vehicles deters $S / R$ drivers in California from driving and becoming involved in crashes. That is, is there a general deterrent impact? Of course, we wouldn't expect all $S / R$ drivers to cease driving and have no crashes, but if there is a general deterrent impact then the crash rates of $S / R$ drivers should be lower once the law became effective.

The research design used to answer this question is an interrupted time series with a nonequivalent no-treatment control, which is quasi-experimental in nature. Clearly, it is not feasible to randomly assign drivers to $S / R$ and validly licensed groups, and then compare their crash rates to determine whether vehicle impoundment works on a general deterrent level. Instead, we rely on multiple observations of crash rates over time to answer this question. Specifically, we have crash rates for 39 separate sequential 28-day time periods prior to January 1, 1995, when the impoundment and forfeiture laws became effective, and 26 such time periods after the laws became effective (on the 40th time period). On the most basic level, we examine whether there is a change in the slope or level of crashes for $S / R$ drivers, relative to control drivers, once vehicle impoundment/forfeiture became effective, which would indicate the presence of a general deterrent effect. With enough observations, the trend of the pre-intervention time period can be assessed, allowing a more valid assessment of changes once the intervention is implemented.

Interrupted time series is a fairly strong quasi-experimental design, but there are some potential threats to both internal and external validity that need to be assessed when using this approach. Perhaps the main threat is what Campbell and Stanley (1963) term "history." This refers to the possibility that something other than the intervention or treatment under investigation might have caused or contributed to observed changes in the measure of interest. One of the best ways to deal with this threat is to add a no-treatment control group to the study (Cook \& Campbell, 1979). This was the approach taken in this study. Drivers who were not $S / R$ and who would not be expected to be influenced by the implementation of the impoundment 
and forfeiture laws (since they are not subject to them) were selected and used as a baseline to compare to $S / R$ drivers. If there are forces other than impoundment/forfeiture that might affect crash rates at the same time these laws came into effect, then the crash rates of both $S / R$ and control drivers should reflect this. Thus, if crash rates dip at the time of impoundment and forfeiture for both $S / R$ and control drivers, we would suspect that there is another force at work affecting crash rates, and this would call into question a general deterrent impact of these laws.

Other potential threats to validity that can occur when using interrupted time series designs include instrumentation and selection. The former occurs when there is a change in the way records are kept that might be confounded with an intervention effect. For example, if the loss of the CHP crash data described earlier had occurred at time period 40 , when impoundment and forfeiture became effective, the drop in crashes due to the missing data might have been confused with the effect of the countermeasures. The author is unaware of any other changes in the data which might have occurred during the study time period.

The other validity threat, selection, happens when the makeup of the treatment group changes at the same time the intervention of interest occurs. For example, if a treatment is powerful enough, subjects may leave and thus be lost to follow-up measurement. In the case of this study, if $S / R$ drivers left California and moved to Nevada because they were afraid of losing their vehicles, then they would be lost to measurement in California and it would look like impoundment was effective, whereas what really happened is that crashes caused by these $S / R$ drivers simply shifted from California to Nevada.

While the above scenario is quite improbable, there is the possibility of a selection bias at another level. As in many other states, the Legislature in California views license suspension/revocation as an attractive "stick" with which to punish people for various traffic and non-traffic offenses. By passing new laws each year prescribing suspension/revocation as a punishment, or modifying existing ones by dropping this sanction, the overall composition of the $S / R$ population will change over time. New groups of $S / R$ drivers may have different crash expectancies, and if there are enough of them, the overall crash rates of $S / R$ drivers might change over time. If such a change occurred, and it corresponded in time with the 
implementation of a countermeasure under investigation, it would represent a rival alternative hypothesis to that of the countermeasure. Similarly, there can be temporal changes in the composition of the control series.

Is selection a problem for this study? New laws prescribing license suspension/revocation for certain offenses did occur during the study period. However, for these to be confounded with the effects of vehicle impoundment/forfeiture, they would have to significantly change the composition and the crash rates of the $S / R$ population at the same time these laws became effective. Given that there are approximately $1,000,000$ drivers in the state who are $S / R$ at any given time, there would need to be a flood of new $S / R$ drivers entering the population in a brief period of time for this to cause a significant change in the crash rates of the $S / R$ population at the same time that impoundment/forfeiture were implemented. Data on the numbers of $S / R$ drivers in the state over time do not support a flood hypothesis. The only way this potential selection bias could even remotely be considered plausible is if it took a long time for the effects of impoundment/forfeiture to appear-that is, if the onset of their effects was quite gradual. We will return to this issue once we have analyzed the intervention effects of impoundment and forfeiture.

\section{Analysis}

The statistical techniques used to analyze the time series data involved autoregressive integrated moving average, or ARIMA, models. ARIMA models were primarily developed and popularized by George Box and Gwilym Jenkins about 30 years ago as a way to circumvent the limitations of modeling time series data using ordinary least squares (OLS) methods (McCleary \& Hay, 1982). The problem with using OLS to analyze time series data is that these techniques assume that the errors in the series are uncorrelated, which is typically not the case with measurements repeatedly taken over time (McCain \& McCleary, 1979).

Any particular time series can be conceptualized as having two different parts. The first is commonly referred to as a deterministic one, and as the name implies, it refers to that portion of the series which is somewhat predictable. There is also a part of the series which is less predictable, and this is called the stochastic part. Even though the stochastic part is less predictable, there is a part of this that can be 
modeled because it is associated with the correlation among measurements in the series, or the autocorrelation in the series. As McCain and McCleary (1979) point out, the primary goal of the ARIMA modeling is to describe this predictable part of the stochastic component, so that only a random portion is left.

However, the goal of this study is not to simply model the autocorrelation in crash rates, but rather to use this as a first step in developing a model which can assess whether the impoundment and forfeiture laws affected the crash rates of $S / R$ drivers. This was done by first developing an ARIMA model for the $S / R$ crash series using SCA statistical software, and then adding what is known as a "transfer function" component to the model to assess possible changes associated with the laws. This transfer function was specified to begin at time period 40 , which corresponds to the date the impoundment and forfeiture laws went into effect (January 1, 1995).

Ideally, we would have some idea of the nature of the intervention associated with the impoundment/forfeiture laws. Did the crash rates of $S / R$ drivers drop abruptly once the laws were implemented, or did they change more gradually? If they dropped, did this impact last permanently, or.was it temporary? For example, if there was a lot of advance publicity about the laws, and if $S / R$ drivers took the threat of losing their vehicles seriously, then many of these drivers may have stopped driving, driven less, or driven more carefully once the laws went into effect, which would be reflected in an abrupt drop in their numbers of crashes. Unfortunately, good statewide data that might shed some light on the form of the intervention are simply not available.

But this isn't necessarily a significant problem, because there is a straightforward method for testing which form of an intervention best fits the observed data (McDowall, McCleary, Meidinger \& Hay, 1980). The three most basic forms of interventions are: abrupt in onset and temporary in duration; gradual in onset and permanent in duration, and; abrupt in onset and permanent in duration. The components for the first two intervention types include a parameter represented by the Greek character "delta," which can be thought of as a description of the rate at which a change in the series occurs; the delta parameter is the key to identifying the most appropriate intervention. 
The method outlined by McDowall et. al. to discover the form of an intervention is to first fit an abrupt temporary component to the ARIMA model. If the delta term estimated from this model is quite large, then the impact is better represented as permanent, so the transfer function in the model is modified to reflect a gradual permanent intervention. If the delta term from this model is very small, then the onset of the intervention is better typified as abrupt, which leaves only the abrupt permanent form. This procedure was used to check various forms of a possible intervention effect for $S / R$ drivers.

However, developing and testing univariate intervention models for $S / R$ drivers doesn't in-and-of-itself provide a reliable indication of a possible general deterrent effect of impoundment/forfeiture, because other events contemporaneous with the implementation of the laws might effect crashes. This is where the control series enters the picture. If the control series also shows a significant drop in crashes at the point impoundment/forfeiture became law, then we have much less confidence that the laws were responsible for the drop in crashes among $S / R$ drivers-some other factor must be at work. So, the next step in the analysis was to build and test univariate intervention models for the control series, using the same methods described above for the S/R series.

In order to provide a more definitive assessment of the impoundment and forfeiture laws, two more types of analyses were conducted. In the first type, the univariate intervention model for $S / R$ drivers was modified to include a second transfer function, the control crash series. The purpose of this was to allow the control crash series to remove variance that it shared with the $S / R$ series from the $S / R$ series, thus allowing for a more sensitive test of the intervention. If this new model for the $S / R$ series still showed a significant intervention effect after accounting for the control series, then added confidence could be placed in the hypothesis that impoundment/forfeiture did affect crashes of $S / R$ drivers. In order to identify the form of the transfer function relationship between the control and S/R crash series, both the CCF approach recommended by McCleary and Hay (1982), and the LTF approach outlined by Liu and Hudak (1992) were employed, the former using BMDP statistical software and the latter using SCA; both approaches yielded very similar results, and only those using the LTF method are reported here. 
The second set of additional analyses utilized SCA to perform joint, simultaneous modeling of interventions for both the $S / R$ and control crash series. The advantage to using simultaneous transfer function (STF) models is that they can account for the correlation between the $S / R$ and control series (there is usually some correlation between series due to exogenous forces), and by doing so better control indirect or spurious effects. Thus, the results from using STF models should more clearly reflect the direct effects of the vehicle impoundment and forfeiture laws on the crash rates of $S / R$ drivers.

SCA was used to perform STF modeling following the approach recommended by Liu (1997). First, the stepwise autoregressive procedure was used to determine whether there was a contemporaneous (lag 0 ) relationship between the $S / R$ and control crash series. Once the results of this procedure were obtained, the linear transfer function (LTF) method was used to see whether the two series were related at time lags other than 0 . If so, this indicates that one series leads the other, and this should be reflected in the transfer function component showing the relationship between the two series. Based on the results from the stepwise autoregressive fitting and LTF procedures, univariate intervention models were developed and estimated for both the $S / R$ and control crash series. These final univariate models were then used in the STF procedure in SCA to jointly estimate the effects of the intervention for both series. 


\section{RESULTS}

Univariate Intervention Analysis

\section{$\underline{S / R}$ crashes}

Because the number of drivers $S / R$ varied across the course of the study, examining only the raw data on the numbers of crashes could prove misleading, since they may only be changing due to the changing number of drivers rather than the impoundment/forfeiture intervention. In order to circumvent this possible bias, a crash rate series was developed by dividing the number of crashes for each time period by the number of drivers $S / R$ during that time period. A plot of the normalized crash series is presented in Figure 1.

The most salient feature of the plot of crashes for $S / R$ drivers is the strong downward trend in crashes over the course of the study. This decrease in the crash rate is somewhat surprising, and while it might indicate that suspension/revocation have become increasingly effective over time, it is also possible that it is due to an artifact of the data collection procedures, or a problem in the data itself. In order to check for potential biases, some exploratory analyses were undertaken. After some investigation, it was discovered that some of the shorter-term suspensions could have been deleted from DMV's driver record database during the first 18 time periods in the study, as part of the department's regular database purge procedures. If this occurred, then it could change the composition of the $S / R$ sample early in the study period; by deleting the shorter-term, and presumably less serious, suspension actions, the S/R sample would be composed of higher-risk drivers in the first 18 time periods who would be expected to have a higher numbers of crashes. 


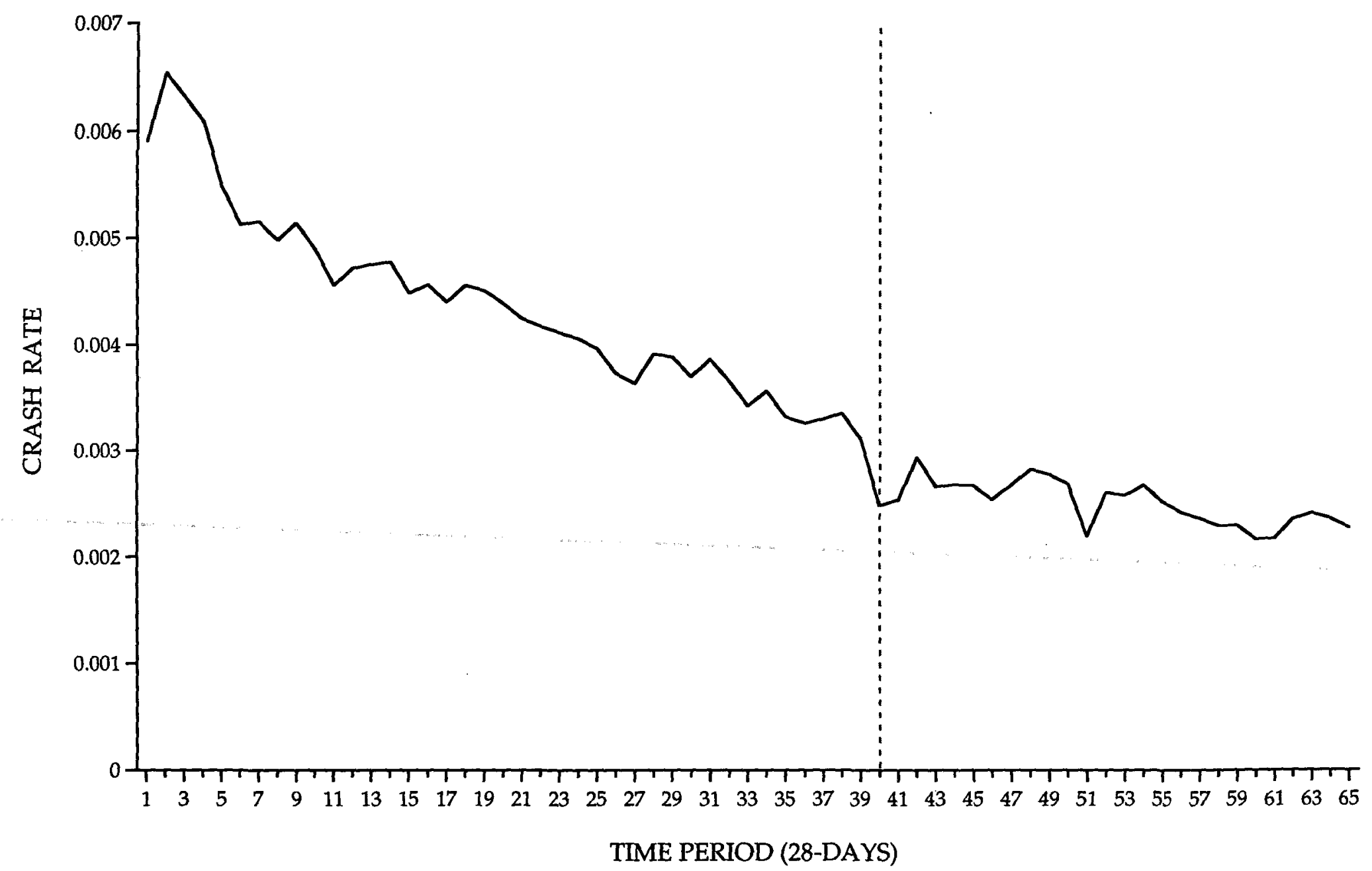

Figure 1. Crash rates for $S / R$ drivers. 
In order to check whether the composition of the $S / R$ sample changed as a result of the purge, data on the reason for the $S / R$ action were obtained for all $S / R$ drivers during 3 time periods: time period 1; time period 19, which is the first time period in which no suspension actions were eligible to be deleted, and time period 40 , when the impoundment/forfeiture interventions occurred. Frequencies were then computed on the suspension reasons for each time period, and the frequencies compared among time periods. The results from these analyses revealed that, while the composition of the $S / R$ sample did change from the first to the nineteenth and fortieth time periods, the changes were relatively insubstantial. The proportion suspended for the most serious offense, DUI, remained constant at about $35 \%$. There was an increase of about $6 \%$ in the proportion of drivers suspended for the less serious offenses of failure to appear for a court hearing or failure to pay a fine, and a corresponding decrease in the percentage suspended for a lack of motor vehicle insurance coverage.

While it is quite unlikely that this minor change in the composition of the $S / R$ sample could have significantly affected the results, a conservative approach was taken where a subset of the ARIMA intervention analyses were conducted using only time periods 19-65, which are known to be unaffected by the department's purge. The results from these analyses led to the same substantive conclusions as those based on all time periods, supporting the argument that the database purge did not bias the study results. The results presented in the report are based on data from all time periods, because the series is relatively short as it is and it is important to include as many data points as possible (the analyses based on time periods 19-65 have their own set of problems due to the very short nature of the series), and also because omitting the first 18 time periods would discard important information about the pre-intervention $S / R$ crash pattern ${ }^{1}$.

A review of the plot of crashes for $S / R$ drivers does not show that there is a significant seasonal component to the crash series. That is, crashes don't appear to cycle or repeat consistently at certain times. For example, if there was a strong yearly

\footnotetext{
${ }^{3}$ The time series results for the subset analyses (periods 19-65) can be obtained from the author upon request.
} 
cycle, we would see a pattern of dips or peaks in crashes every 13 time periods, but this is not apparent here. A vertical line has been added at time period 40 , the point at which the impound and forfeiture laws became effective. There is a visible abrupt drop in crashes at this point, corresponding to the effective date of the laws, although it appears that this is not maintained since the crash rate increases a short time later.

The strong downward trend in the series needs to be incorporated in the model prior to developing an ARIMA component. This is done by differencing the series, or subtracting from each observation the preceding observation; the results of this operation are portrayed in Figure 2.

Note that the differencing operation has removed the downward trend in the crash series. There is some noticeable variation in the series at the very beginning, and then again around the point of intervention, but there does not appear to be any systematic increase or decrease in variance over the course of the series which would indicate a potential problem of variance nonstationarity. 


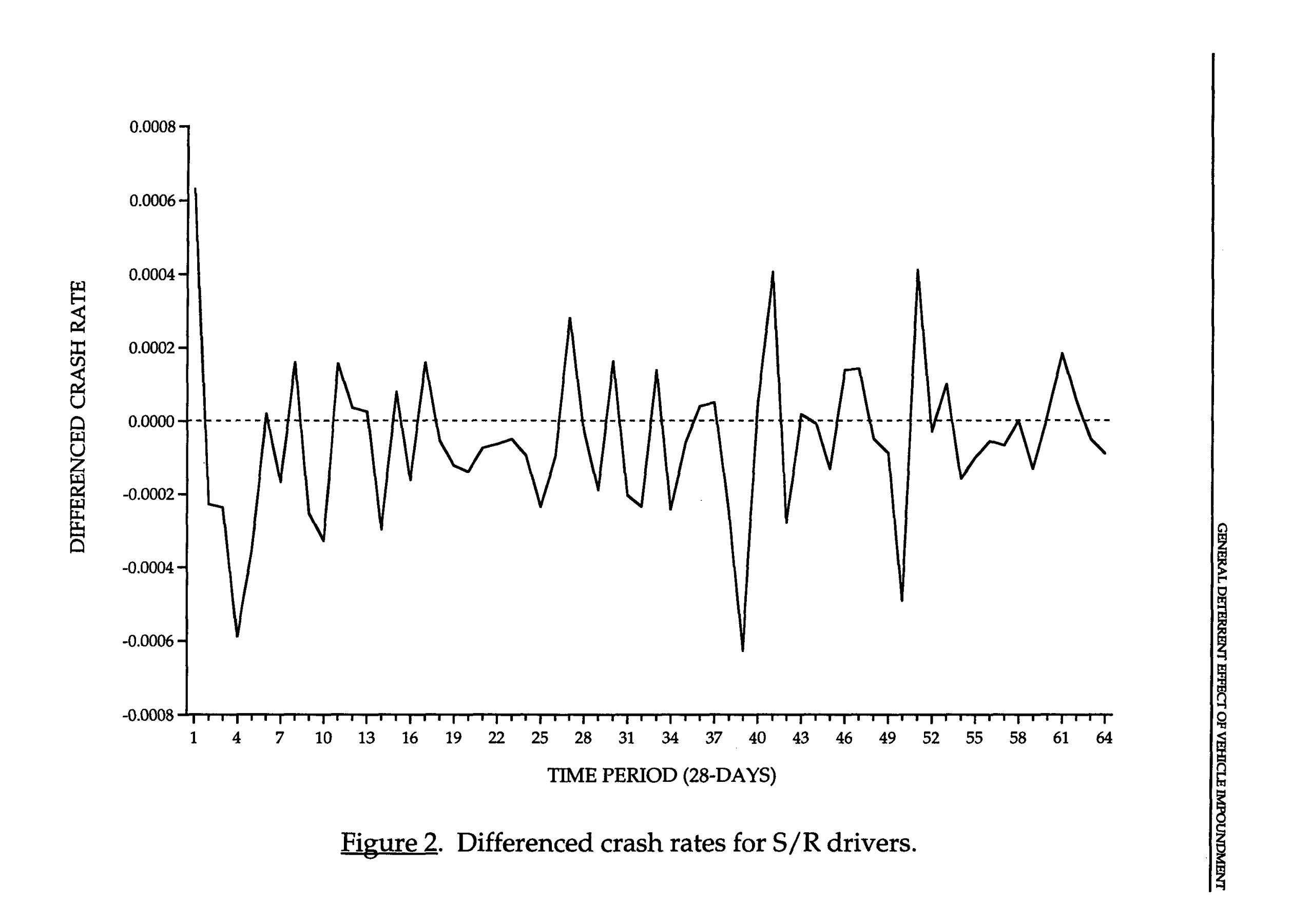


SCA was used to develop a simple model of the differenced $S / R$ crash series. The iterative model identification, estimation and diagnosis procedure recommended by McCleary and Hay (1982) was used to define this model. Based on the autocorrelation function (ACF) and partial autocorrelation function (PACF) of the residuals of various models, a parsimonious model with only a regular differencing term $(0,1,0)$ best fit the data; the $Q$ statistic from the residuals of this model had a $p$ value of approximately .4 , indicating that the residuals were not different than white noise and that the model was thus acceptable.

Next, an intervention component was added to the model to assess whether there was an abrupt temporary impact associated with impoundment/forfeiture. The residuals from this initial intervention model indicated that a moving average (MA) term at lag 1 improved the fit of the model. Table 1 presents the parameter estimates and other statistics from the abrupt temporary intervention model for crashes involving $S / R$ drivers.

Table 1

The Effects of an Abrupt Temporary Intervention of Vehicle Impoundment on Crash Rates for S/R Drivers

\begin{tabular}{llll}
\hline \multicolumn{1}{c|}{ Parameter } & Estimate & Std error & $T$ value \\
\hline Constant & .000059 & .000018 & -3.14 \\
Omega & -.0006 & .0002 & -3.40 \\
Delta & .6816 & .2433 & 2.80 \\
MA (1) & .2463 & .1147 & 2.15 \\
\hline & $R M S=.00019426$ & \\
\hline
\end{tabular}

The results from the ARIMA analysis show that both the omega term representing the change in the series at the point of intervention, and the delta term, portraying the rate of change, are statistically significant, which supports the hypothesis that an abrupt temporary drop (the omega estimate is negative, indicating a decrease in 
crashes) in the crash rate of $S / R$ drivers took place at the time the impoundment/forfeiture countermeasures became law. The $Q$ statistic of the model residuals has an associated $p$ of about .6 , indicating that the residuals of the model are consonant with a white noise process; this, plus the plot of the ACF, which shows no significant spikes at lower lags, indicates that the model is acceptable.

The delta term in the model is moderate in size, indicating that the abrupt effect is not likely to be permanent. This seems to correspond with the data, which shows an abrupt drop in crashes followed by an increase several time periods later. The abrupt drop amounts to a $13.6 \%$ decrease in crash rates at the point of intervention. However, this drop in crashes wears off fairly quickly: approximately $78 \%$ of the effect is gone after only 4 time periods (112 days), and it has almost completely vanished $(99.3 \%)$ after one year.

In order to confirm the results of the abrupt temporary model, the intervention term was modified and both gradual permanent and abrupt permanent models were developed and analyzed. The former had a delta parameter that was small and insignificant, indicating that the intervention effect was abrupt rather than gradual, and while the latter model showed the omega term to be significant, the residual mean square (RMS) of this model was higher than that of the abrupt temporary one, indicating that an abrupt temporary model best fit the data. This makes intuitive sense, given both the pattern of the effect shown on a plot of the crash rate for $S / R$ drivers (Figure 1), as well as the aforementioned statistics on the quick dissipation of the effect. As noted earlier, interpretation of the intervention parameter as a true effect requires comparison with the control series, as presented below.

\section{Control crashes}

As with the $S / R$ crash series, the crash data for control drivers was normalized by dividing the number of crashes in each time period by the number of drivers in that time period, which formed a crash rate series. A plot of crash rates for control drivers in shown in Figure 3. 


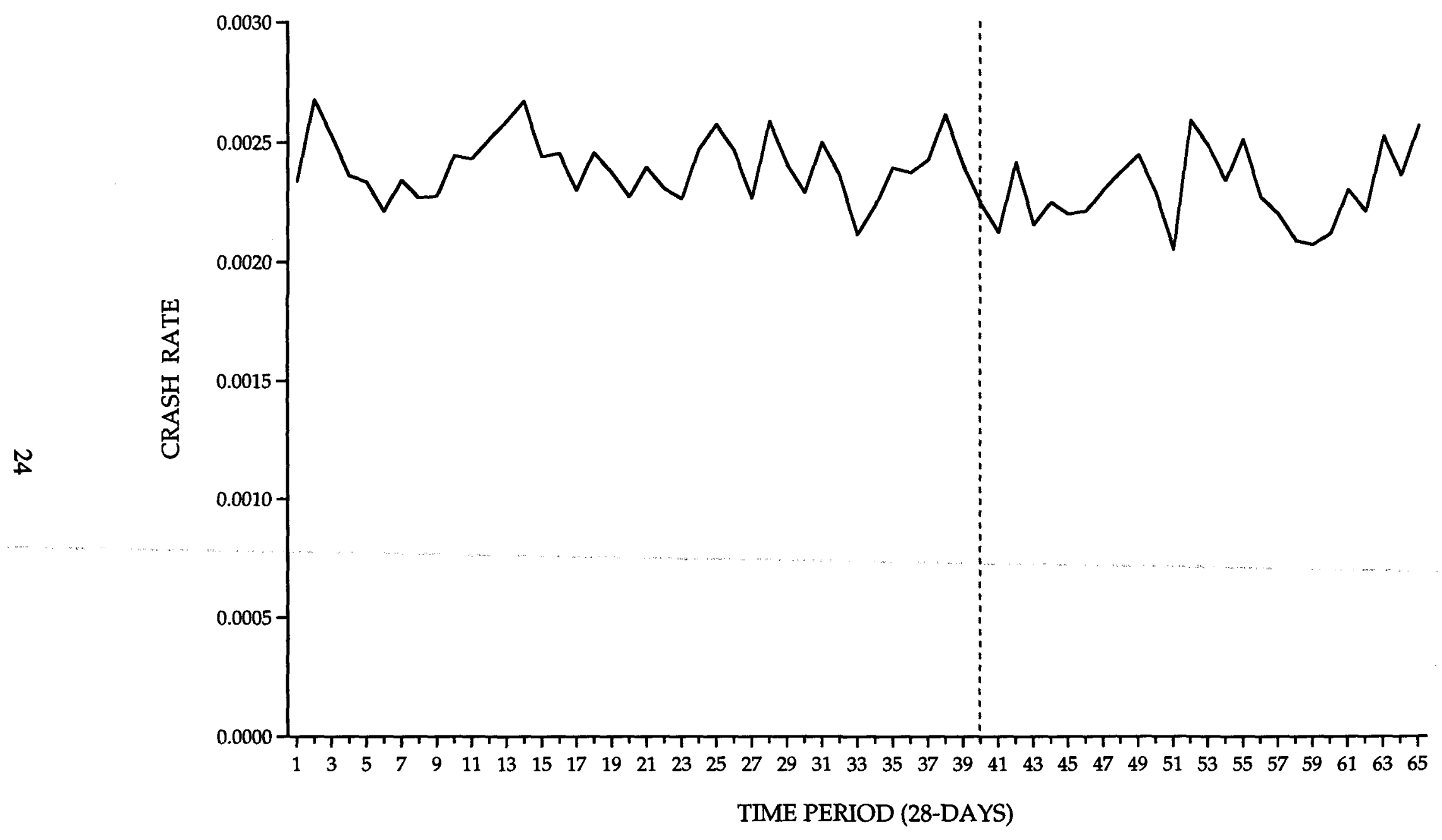

Figure 3. Crash rates for control drivers. 
In contrast to the $S / R$ crash rates, the rates for control drivers do not appear to trend upward or downward over the study period. And, while there is some variation in crashes from time period to time period, there is no systematic seasonal pattern evident in the series. Finally, there does not seem to be much change in variance over time; this stationarity in variance allows us to use the crash series as it is, without needing to transform it.

Because the control crash rate doesn't exhibit a trend, there is no need to difference the series to make it stationary, as was done with the $S / R$ crash series. In Figure $3, a$ vertical line has been added at time period 40 , the point at which the impoundment and forfeiture laws became effective, in order to facilitate a visual inspection of the data. There is a visible abrupt decline in the crash rate that corresponds in time to the laws, with a rise in crashes occurring a few time periods later. This abrupt decline at time period 40 with a fairly quick upturn in the crash rate mirrors the pattern found in the crash rate for $S / R$ drivers, as a comparison of Figures 1 and 3 will show.

SCA was used to examine the correlation structure in the crash rates for control drivers. The initial models, minus a transfer function intervention component, showed that a model with MA terms at 1 and 10 best fit the data and yielded residuals that were distributed as white noise ( $p$ value of $Q$ statistic of residuals $=.36$ ) and had no significant spikes at lower order lags. Thus, this initial model of the crash series was acceptable.

Once this initial model was developed and evaluated, an intervention component was added to the model specifying an abrupt temporary intervention in the crash data at time period 40 . The parameter values and other relevant statistics are presented in Table 2. 
Table 2

The Effects of an Abrupt Temporary Intervention of Vehicle Impoundment on Crash Rates for Control Drivers

\begin{tabular}{lcccc}
\hline \multicolumn{1}{c|}{ Parameter } & Estimate & Std error & $T$ value \\
\hline Constant & .0024 & .000032 & 74.68 \\
Omega & -.0002 & .000063 & -3.16 \\
Delta & .8268 & .1092 & 7.57 \\
MA (1) & -.2346 & .1204 & -1.95 \\
MA (10) & -.9644 & .0885 & -10.90 \\
.- & $\mathrm{RMS}=.00010674$ & \\
& $Q_{(24)}=(33.3) ; p=.098$ & \\
\hline
\end{tabular}

The results from the ARIMA analysis indicate that there was a statistically significant abrupt temporary reduction in the crash rate of control drivers at the point the vehicle impoundment and forfeiture laws became effective. The abrupt

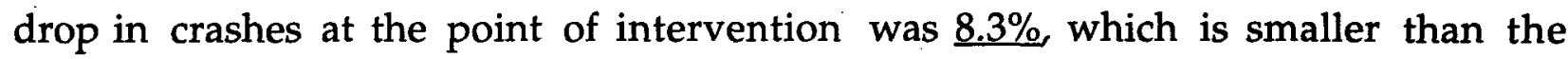
drop for $S / R$ crashes but is of the same general magnitude. The larger delta term here means that the abrupt drop in crashes for control drivers lasts longer before returning to a higher level than does the drop for $S / R$ drivers, but the effect for control drivers still vanishes fairly quickly; more than half of the effect is gone after only 4 time periods (112 days), and it is mostly gone (91.5\%) after one year. It should be noted that this model is acceptable, but just barely; the theta value for the MA (10) parameter is approaching the limit of invertability (the limit is $|1.0|$ ), and the $p$ value for the $Q$ statistic for the residuals is about .10, which is close to the value where we would begin to suspect that the residuals are not white noise.

Because the abrupt temporary model was somewhat unstable, both gradual permanent and abrupt permanent intervention models were developed and estimated. The results from the gradual permanent model for control drivers were similar to those for $S / R$ drivers; for both driver groups, the deltas were small and insignificant, indicating that an abrupt intervention pattern more closely fit the data 
than did a gradual one. In contrast, the intervention parameter for the abrupt permanent model for the control crash rate series was statistically significant, indicating that this model also fits the crash rate data. So, as was the case with the $S / R$ crash series, we have two abrupt intervention models that fit the data, one specifying a temporary effect that dissipates relatively quickly, the other identifying the effect as permanent. While this apparent contradiction deserves additional exploration, the abrupt temporary model fits the control crash data better; a visual inspection of Figure 3 clearly shows that the drop in crashes returns to a higher level within a few time periods. In fact, the post-intervention mean crash rate is higher than the pre-intervention rate at both 1 and 2 years subsequent to the intervention. Although both the abrupt temporary and abrupt permanent intervention models fit the crash series for control drivers, the abrupt temporary model was chosen as the final model to represent the series because it was more consistent with the crash data and, while it is not a strong model, it is acceptable.

Intervention and Transfer Function Analyses: S/R Crashes

The first set of analyses, which used univariate intervention models to compare crashes involving $S / R$ drivers to those of control drivers, revealed that the crash rates for both groups dropped at the point the vehicle impoundment and forfeiture laws became effective. In order to explore this further, a second set of analyses was run using control crashes as a covariate for $S / R$ crashes, so as to remove any noise patterns shared by the two series. However, before this could be done, preliminary analyses needed to be conducted to discover the nature of the relationship between the two series.

The linear transfer function, or LTF, procedure in SCA was used to explore the relationship between $S / R$ and control crashes. The control crash series was entered as a transfer function in the univariate intervention model developed for $S / R$ drivers, with lagged relationships ranging from lag 0 to lag 6 specified for the transfer function component. Several analyses were performed on this model in an iterative fashion, removing insignificant lagged components; the final model showed that control crashes were related only contemporaneously (at lag 0 ) to $S / R$ crashes ( $t$ value $=6.46 ; p<.001$ ). In other words, these results show that one series 
does not lead the other in time, but that there is a significant pattern of shared noise at the same points in time.

Based on the results of the LTF analyses, the $S / R$ crash model was modified to include the control crash series at lag 0 as a transfer function. This new model was estimated and the results are displayed in Table 3.

Table 3

Abrupt Temporary Intervention Effects on S/R Crashes Using Control Crashes as a Transfer Function

\begin{tabular}{lcccc}
\hline \multicolumn{1}{c|}{ Parameter } & Estimate & Std error & $T$ value \\
\hline Constant & .0000594 & .0000193 & -3.09 \\
Omega & -.0005 & .0001 & -3.21 \\
Delta & .5401 & .3234 & 1.67 \\
Control crashes & .7405 & .1147 & 6.46 \\
\hline & RMS $=.00015414$ & \\
& & $Q_{(26)}=(30.7) ; p=.240$ \\
\hline
\end{tabular}

All parameter estimates are within the required bounds, and the $p$ value of the $Q$ statistic for the residuals indicates that the residuals can be considered white noisethis, and the absence of spikes at lower-order lags of the ACF, indicate that the model is acceptable. The MA term at lag 1 which was in the previous univariate intervention model for $S / R$ drivers became insignificant once the control crash series was introduced into the model, and so it was dropped. The control crash series is highly statistically significant, reflecting the similar noise patterns that control and $S / R$ crashes share.

Interestingly, both the omega and delta intervention terms drop in size with the addition of the control crash series, probably because control crashes also show an 
abrupt drop at the time of the impoundment and forfeiture laws and thus remove some of this effect from $S / R$ crashes. $^{2}$ In fact, the intervention changes from being statistically significant, as it was before the introduction of control crashes, to merely suggestive of an effect, with the $p$ value of the delta term being .099 . This result is not surprising, and is consistent with the results of the univariate intervention models for $S / R$ and control drivers, both of which show an intervention effect. This intervention plus transfer function model is a better and more sensitive model than the univariate model for S/R drivers, as reflected in its lower RMS $(.000154$ versus .000194).

\section{Simultaneous Transfer Function Analyses}

The final set of analyses conducted on the crash rate data involved simultaneously estimating intervention models for both $S / R$ and control drivers. The two previous sets of analyses showed that both $S / R$ and control crash rates significantly dipped at the point of intervention, and the intervention effect for $S / R$ drivers became only marginally significant once the noise in the control series was accounted for in the model. Given these results, this final set of analyses used STF models to better control any indirect or spurious effects by accounting for the correlation between the $\mathrm{S} / \mathrm{R}$ and control crash series.

In order to properly specify STF models, it is important to determine whether a contemporaneous relationship exists between the series (Liu, 1997). This was done by using SCA to perform autoregressive (AR) stepwise fitting, which can be thought of as a stepwise regression with time lags. The results from the AR stepwise models showed that there was a statistically significant correlation in all matrices of the residual series ( $p$ for all residual matrices $<.001$ ), which indicates that the $S / R$ and control series are contemporaneously related.

${ }^{2}$ This same effect is seen when the $S / R$ crash series is introduced as a transfer function into the univariate intervention model for control crashes. The results from such an analysis, which are not presented here because they are not of practical importance, also show that the omega and delta terms drop in significance once the $S / R$ crash series is included in the model, presumably because of shared noise patterns between $S / R$ and control crashes. 
The point in checking for a contemporaneous relationship between the $S / R$ and control crash series is to determine whether a lag 0 relationship needs to be included in the STF model; these results indicate that such a relationship does need to be included. However, this isn't the whole story, because it still isn't known whether one series leads the other contemporaneously. Said another way, although the results indicate that a contemporaneous relationship between the series exists, there may also be other time lags at which the two series are related. ${ }^{3}$ Thus, the second set of preliminary analyses used the LTF procedure to further explore the nature of the relationship between $S / R$ and control crashes.

Using SCA, LTF models for both $S / R$ and control crash series were specified and estimated. In these models, one series was used as a transfer function in the estimation of the other, with potential lags from 0 to 6 defined in the model. The results from both the $S / R$ and control crash models showed that neither series led the other contemporaneously; there was only evidence for a lag 0 relationship between the two. It is important to note that this also indicates that the control series is exogenous in the simultaneous model (i.e., it can't be predicted by the $S / R$ series).

Based on the results of these preliminary analyses, the STF modeling procedure in SCA was utilized to develop and simultaneously estimate intervention models for both the $S / R$ and control crash series. A transfer function representing the abrupt temporary intervention at time period 40 was included in both the $S / R$ and control crash equations, while the contemporaneous relationship between the two was entered in the $S / R$ equation only (the contemporaneous relationship is entered in only one of the equations; Liu, 1997). The results of the STF analyses are presented in Table 4.

\footnotetext{
${ }^{3}$ Note that a necessary (but not sufficient) condition to establish causality is when two phenomena are related and there is a temporal order to this relationship. If one time series leads another contemporaneously, this potentially indicates a causal relationship. In contrast, when two series are related only contemporaneously (no temporal order), then there is a correlation between the two, but there is no causality involved. Theoretically, we would expect only a contemporaneous relationship between the $S / R$ and control crash series; it is highly unlikely that crashes in one group could cause crashes in the other group at a later point in time, but it is likely that some exogenous force, such as the level of traffic enforcement, could affect crashes for both groups at the same time.
} 


\section{Table 4}

STF Analyses to Jointly Estimate Abrupt Temporary Intervention Effects for Both S/R and Control Crashes

Summary for $S / R$ crashes

\begin{tabular}{l|c|c|c}
\hline \multicolumn{1}{c|}{ Parameter } & Estimate & Std error & $T$ value \\
\hline Constant & .0000598 & .0000193 & -3.10 \\
Omega & -.0005 & .0001 & -3.27 \\
Delta & .5282 & .3193 & 1.65 \\
Control crashes & .7062 & .1146 & 6.16 \\
\hline
\end{tabular}

Summary for control crashes

\begin{tabular}{l|l|l|c}
\hline \multicolumn{1}{c|}{ Parameter } & Estimate & Std error & $T$ value \\
\hline Constant & .0024 & .0000322 & 73.31 \\
Omega & -.0002 & .0000720 & -2.70 \\
Delta & .8454 & .1162 & 7.28 \\
MA (1) & -.2206 & .1234 & -1.79 \\
MA (10) & -.7467 & .0923 & -8.09 \\
\hline
\end{tabular}

The results for the STF model for $S / R$ crashes are quite similar to those for $S / R$ crashes using control crashes as a transfer function, which can be verified by comparing the statistics in the top half of Table 4 with those in Table 3. Thus, not much extra sensitivity or accuracy was gained using the STF procedure. The explanation for this can be found in the error correlation matrix from the STF model, where the off-diagonal element shows the degree to which the two series share a similar noise pattern-this value was .07 , indicating that not much noise was shared between the two (note that much of the variance between the series has already been captured by including the lag 0 relationship in the STF model).

The STF results indicate that there is, at best, only marginal ( $p$ for delta in $S / R$ equation $=.099$ ) evidence for an abrupt temporary impact of vehicle impoundment on the crashes of $S / R$ drivers. In contrast, the STF results show that there is a statistically significant drop in crashes for control drivers at the point that vehicle impoundment/forfeiture were implemented. The STF procedure estimated the 
equations for $S / R$ and control crashes simultaneously, so that each equation more clearly reflects the direct effects of the intervention on the crash rates it is modeling. Given that the results obtained from using this procedure showed a statistically significant intervention effect for control drivers, and only a suggestive effect for $S / R$ drivers, it does not appear that vehicle impoundment/forfeiture had a substantial effect on the $S / R$ drivers it targets. Cross correlation matrices were computed for the residuals from the $S / R$ and control equations in the STF model; there were no significant spikes at any lags, indicating that the STF model was properly specified and acceptable. 


\section{DISCUSSION}

Before discussing the results of the time series analyses, the limitations inherent in the data and study design will be reviewed so that appropriate conclusions can be drawn. The first point that needs to be mentioned is that the study results only generalize to $S / R$ drivers, and not to unlicensed drivers. The vehicle impoundment and forfeiture laws apply to both of these groups, but as explained in the Method section of the paper, it is very difficult to identify and study unlicensed drivers, and so they were not included in the study. If impoundment/forfeiture affect unlicensed drivers differently than they do $S / R$ drivers, then the results of this study will not completely reflect the impact of these countermeasures.

The quasi-experimental design used in this study, interrupted time series with a nonequivalent no-treatment control group, controls most threats to internal and external validity. One common threat to time series designs is that some event or historical force other than the intervention of interest may be responsible for a change in the series. However, history is largely controlled in this study through the use of the control crash series; even if some extraneous event influences crash rates in general at the same point that the intervention occurs, it is unlikely that this will be confused with the effect of the intervention because both $S / R$ and control crashes will reflect the impact of this extraneous event.

In addition to generalizability and design issues, there is the problem that some of the crash data for both groups early in the study period was lost and is unrecoverable. The missing data was estimated for both groups using the same procedure in order to minimize any potential bias. Fortunately, the point at which the data is missing occurs well before the intervention-about 2 years prior-and only involves 2 of the 65 time periods. The estimates of the missing data appear plausible, if somewhat conservative, and would not be expected to have much practical influence on the intervention effect estimates.

It also appears that the purge of the driver record database undertaken regularly by the DMV may have somewhat affected the composition of drivers in the $S / R$ sample group early in the study period. As detailed in the Results section, some of the shorter suspension actions (primarily failure to appear for a court hearing or 
failure to pay a fine) may have been purged during the first 18 time periods, so that these drivers would have been omitted from the sample. Analyses did show that there were about $6 \%$ more $S / R$ drivers at the beginning of the study who were suspended for the somewhat more serious offense of lack of motor vehicle insurance, but this change is fairly minor and subsequent ARIMA intervention analyses conducted on only those time periods unaffected by the purge demonstrated that the purge did not bias the findings.

Finally, it would have been desirable to have a longer series, especially if the additional data points occurred after the intervention. Cook and Campbell (1979) recommend a minimum of 50 data points for time series designs; although we have more than that, the fact that the series is not long and that the intervention does not occur in the middle of the series means that the statistical power is not as great as it could have been with more data. Ultimately though, given the pattern of the results, it is unlikely that greater statistical power would lead to conclusions that are substantively different than those found here.

\section{Results of Analyses}

Before conducting the ARIMA intervention analyses, the crash rates for both $S / R$ and control drivers were plotted and examined. Surprisingly, the rates for $S / R$ drivers dropped substantially over the course of the study, especially prior to the implementation of the vehicle impoundment/forfeiture laws (see Figure 1). It is likely that some of this decline in the crash rate very early in the study is due to the change in the composition of the S/R sample which resulted from DMV's database purge, but the purge can only account for a modest proportion of the drop. If the first 18 time periods subject to the purge are omitted, there remains a strong downward trend. It thus appears that there may be an actual decline in the $S / R$ crash rate over time, suggesting the possibility that suspension/revocation have become increasingly effective. Because this issue was not of primary interest to this study it was not explored in detail, but it is both intriguing and important and should be the focus of future research. An analysis of FARS data might prove illuminating, at least as it relates to the fatal crash involvement of $S / R$ drivers.

Three different sets of analyses were conducted, starting with a simple univariate intervention model, then adding the control group's crash rate as a transfer function 
to account for shared variance in the two crash series, and finally concluding with a complex procedure where univariate intervention models were developed and simultaneously estimated for both $S / R$ and control crashes. The picture that emerges is that the majority of the apparent reduction in crashes involving $S / R$ drivers can be attributed to exogenous factors affecting drivers in general.

The results from the univariate intervention model for $S / R$ crashes demonstrate that a statistically significant drop in crashes occurred for $S / R$ drivers at the same time that the impoundment and forfeiture laws became effective. Based on both a visual inspection of the crash data and the results from the statistical modeling, it appears that this abrupt drop in crashes was only temporary, and that crashes again rose back to their pre-law level fairly quickly. At this point, where we have examined only the $S / R$ crash rates, the evidence supports the hypothesis that there is a general deterrent impact of vehicle impoundment and forfeiture on the $S / R$ driving population that it targets; crashes for this group drop abruptly once these measures become law. ${ }^{4}$

However, at this point we can't be sure that the drop in crashes was due to the impoundment/forfeiture laws-what if some other historical event occurred at the same time that caused crashes to fall? This is where the control crash series becomes valuable. If impoundment/forfeiture were responsible for the drop in crashes for $\mathrm{S} / \mathrm{R}$ drivers, then the crash rate for control drivers should not drop at the time the laws became effective, because the average driver who is not $S / R$ is not subject to impoundment or forfeiture. In essence, the laws don't pertain to non-S/R, or control, drivers so their crash rates should remain uninfluenced by the implementation of the laws. The results from the univariate intervention analyses for control crashes show that there is evidence of a significant drop in crashes for these drivers coinciding with implementation of impoundment/forfeiture. This changes the interpretation of the drop in crashes for $S / R$ drivers, and also illustrates the importance and power of including a no-treatment control group in the study.

\footnotetext{
${ }^{4}$ Note that an alternative explanation for the drop in crashes to that of the effects of vehicle impoundment/forfeiture is that these new penalties for DWS/DWU caused S/R drivers to less frequently report crashes to authorities (the crash data is comprised of such incidents reported to DMV by law enforcement, as well as property-damage-only crashes reported to the department by the drivers themselves). While this appears unlikely, it was checked by examining a plot of fatal/injury crashes only (which would not be subject to a change in reporting by drivers), which also showed this same drop at the point the new laws were implemented, demonstrating that this reporting change hypothesis does not explain the drop observed in all crashes.
} 
Because the crash rates for both $S / R$ and control groups drop abruptly at the point of impoundment and forfeiture, it appears that some other external factor was responsible for the majority of the drop, not the laws. It is possible that there was some general deterrent effect of the laws, because the drop in crashes for $S / R$ drivers was larger $(13.6 \%)$ than the corresponding drop for control drivers $(8.3 \%)$. However, even if this difference represents a small general deterrent effect, the fact that more than three-quarters of the effect has dissipated after about 4 months means that it is of little practical significance.

This drop in crashes for both $S / R$ and control drivers was explored further by running two more sets of analyses that examine the $S / R$ crash rates while more directly accounting for the patterns of control crashes. Both sets of these more complex analyses agree with one another, and also confirm the results of the univariate analyses for both $S / R$ and control drivers. When control crashes are included in the models, either as a transfer function or as a separate equation in a system of joint modeling, the evidence of a statistically significant intervention effect on $S / R$ drivers declined to a marginally significant level.

\section{Conclusions and Recommendations}

This study did not find compelling evidence of a general deterrent impact of vehicle impoundment and forfeiture on crashes for one of the main groups the law targets-S/R drivers. While crashes for $S / R$ drivers did drop temporarily at the time the laws became effective, crashes also dropped for control drivers, who are not $S / R$ and thus wouldn't be expected to be influenced by the laws. In addition, the nature of the drop doesn't fit the pattern we might expect if the change was due to impoundment/forfeiture. It doesn't seem likely that $S / R$ drivers would abruptly change their driving behavior the moment the laws became effective, only to again revert back just a few months later. Yet this is what the crash pattern looks like, as an examination of Figure 1 shows. A more plausible explanation is that some other external factor, or possibly even another flaw in the data, occurred at the same time the laws became effective and was the major factor in the decline in crash rates for all drivers.

This lack of a general deterrent impact is somewhat surprising in light of the results from the specific deterrent study of vehicle impoundment in California. That study 
(DeYoung, 1997a) showed that $S / R$ and unlicensed drivers whose vehicles were impounded had significantly fewer subsequent crashes and traffic convictions than similar $S / R$ and unlicensed drivers whose vehicles were not impounded. These findings were not only statistically significant, they were substantively significant as well, with effect sizes ranging from about $18 \%$ to $38 \%$. Similar results have been reported from specific deterrent studies conducted in other regions (Beirness, Simpson \& Mayhew, 1997; Crosby, 1995; Voas, Tippetts \& Taylor, 1997; Voas, Tippetts \& Taylor, 1998). Unfortunately, there are no other studies of the general deterrent impact of vehicle impoundment and forfeiture which might help to shed light on the findings from this study. Voas and Tippetts (1995) did evaluate the general deterrent impact of the vehicle-based sanction of marking license plates in Washington and Oregon, finding insignificant results in the former and significant ones in the latter, but marking license plates is too different from actually seizing and impounding vehicles to generalize the results directly to this study.

These California results seem to be telling us that if you seize and impound the vehicle of someone driving while $S / R$, that this will have a significant impact in reducing their driving risk (specific deterrence), but that the threat of impounding and forfeiting vehicles does not change the behavior of $S / R$ drivers who are in a position to continue driving and becoming involved in crashes (general deterrence). General deterrence theory posits that people's perceptions of the consequences of violating a law influence their propensity to offend, and that if they perceive the punishment to be sufficiently certain, swift, and/or severe, that they will be less likely to violate. The results from this study suggest that, at least in the first two years following the enactment of vehicle impoundment and forfeiture, $S / R$ drivers did not perceive this punishment to be severe, swift or certain enough to deter them from offending.

Impoundment is administrative in nature, and while forfeiture does involve the courts, the initial seizing of the vehicle is done by peace officers without court participation; this administrative nature of the laws means that they are carried out swiftly by officers at the time of apprehension. They would also appear to be fairly severe-the cost of retrieving an impounded vehicle can approach $\$ 800$ or more, and there is considerable inconvenience associated with the loss of a vehicle. The certainty of the punishment is more of an open question. While the laws' administrative nature means that cases won't languish in the courts, many law 
enforcement agencies, at least initially, did not uniformly apply the laws but rather used them selectively, targeting the more serious offenders. It is possible that this initial selective application became known to $S / R$ drivers, so that they didn't take the laws seriously.

Another possible explanation for the failure of this study to detect a significant general deterrent impact is that there was insufficient advance publicity about the laws to inform $S / R$ drivers of the new countermeasures; general deterrence cannot operate unless potential offenders are aware of the new laws and the punishment for violating them. While it is not known to what extent radio and television publicized vehicle impoundment/forfeiture, the coverage in the print media was not extensive. There were only 37 total articles about impoundment; forfeiture in the largest newspapers in the state (San Francisco Chronicle, Sacramento Bee, San Jose Mercury News, Los Angeles Times and the San Diego Union-Tribune) prior to the implementation of the laws, and 39 articles afterwards. This total of 76 articles compares to 156 articles on California's Administrative Per Se License Suspension law (Bloch, 1991), which was shown to have a significant general deterrent impact (Rogers, 1995). It is not known whether the print media coverage, as well as an unknown amount of radio and television publicity, was sufficient to inform $S / R$ drivers of the new laws and the penalties that they would incur if they drove while suspended.

If the lack of knowledge of the laws or their initial selective application are responsible for the lack of a general deterrent impact, then it is possible that such an impact may appear later. Anecdotal evidence (unfortunately, statewide data do not exist on the implementation of the laws) suggests that law enforcement has steadily increased their use of impoundment and forfeiture, partly because more than a dozen grants have been awarded to law enforcement agencies by the state Office of Traffic Safety to initiate impound/forfeiture programs. If the use of these measures is increasing, then it is possible that a general deterrent impact of the laws is occurring, but that its onset is delayed. Another study with additional post-law data might reveal such an effect, but any study would confront significant methodological problems, such as where to place, apriori, an intervention effect. All that can be said at this point is that there is no strong evidence to support a general deterrent impact of vehicle impoundment and forfeiture in California. 
What policy recommendations arise from this study? While there is no convincing evidence at this point of a general deterrent impact of vehicle impoundment/forfeiture, the strong evidence of a substantial specific deterrent impact found in an earlier study (statistically significant reductions in crashes ranging from $25 \%$ to $38 \%$, in total traffic convictions ranging from $18 \%$ to $22 \%$, and DWS/DWU convictions ranging from $24 \%$ to $34 \%$; DeYoung, 1997a) provides a compelling argument in support of vehicle impoundment. The longer that these measures are used, and the more consistently and widely they are applied, the more likely it is that they will eventually exert a significant general deterrent impact as well as a specific deterrent one. These laws deserve continued support, both financially and politically. 


\section{REFERENCES}

Beirness, D. J., Simpson, H. M., \& Mayhew, D. R. (1997). Evaluation of administrative license suspension and vehicle impoundment programs in Manitoba. Ottawa, Ontario: Traffic Injury Research Foundation of Canada.

Bloch, S. (1991). Interim assessment of California's $.08 \%$ BAC and APS laws. Los Angeles, CA: Automobile Club of Southern California.

California Highway Patrol. (1996). 1996 annual report of fatal and injury motor vehicle traffic collisions. Sacramento: Author.

Campbell, D. T., \& Stanley, J. C. (1963). Experimental and quasi-experimental designs for research. Chicago, IL: Rand McNally College Publishing Company.

Cook, T. D., \& Campbell, D. T. (1979). Quasi-experimentation: Design and analysis issues for field settings. Boston, MA: Houghton Mifflin Company.

Crosby, I. B. (1995). Portland's asset forfeiture program: the effectiveness of vehicle seizure in reducing rearrest among "problem" drunk drivers. Portland, OR: Reed College Public Policy Workshop.

DeYoung, D. J. (1990). Development, implementation and evaluation of a pilot project to better control disqualified drivers. Sacramento: California Department of Motor Vehicles.

DeYoung, D. J. (1997). An evaluation of the effectiveness of alcohol treatment, driver license actions and jail terms in reducing drunk driving recidivism in California. Addiction, 92(8), 989-997.

DeYoung, D. J. (1997a). An evaluation of the specific deterrent effect of vehicle impoundment on suspended, revoked and unlicensed drivers in California. Washington, D.C.: National Highway Traffic Safety Administration. 
DeYoung, D. J., Peck, R. C., \& Helander, C. J. (1997). Estimating the exposure and fatal crash rates of suspended/revoked and unlicensed drivers in California. Accident Analysis \& Prevention, 29(1), 17-23.

Hagen, R. E., McConnell, E. J., \& Williams, R. E. (1980). Suspension and revocation effects on the DUI offender. Sacramento: California Department of Motor Vehicles.

Liu, L. M., \& Hudak, G. B. (1992). Forecasting and time series analysis using the SCA statistical system, Volume 1. Oak Brook, IL: Scientific Computing Associates Corporation.

Liu, L. M. (1997). Forecasting and time series analysis using the SCA statistical system, Volume 2. Oak Brook, IL: Scientific Computing Associates Corporation.

McCain, L. J., \& McCleary, R. (1979). The statistical analysis of the simple interrupted time-series quasi-experiment. In T. D. Cook and D. T. Campbell, Quasi-experimentation: design and analysis issues for field settings (pp. 233-293). Boston, MA: Houghton Mifflin Company.

McCleary, R., \& Hay, R. A. (1982). Applied time series analysis for the social sciences. Beverly Hills, CA: Sage Publications, Inc.

McDowall, D., McCleary, R., Meidinger, E. E., \& Hay, R. A. (1980). Interrupted time series analysis. Beverly Hills, CA: Sage Publications, Inc.

National Safety Council. (1997). Accident facts. Itasca, IL: Author

Peck, R. C. (1991). The general and specific deterrent effects of DUI sanctions: A review of California's experience. Alcohol, Drugs and Driving, 7(1), 13-42.

Peck, R. C., \& Healey, E. J. (1995). California's negligent operator treatment program evaluation system, 1976-1995. Sacramento: California Department of Motor Vehicles. 
Rodgers, A. (1994). Effect of Minnesota's license plate impoundment law on recidivism of multiple DWI violators. Alcohol, Drugs and Driving, 10(2), 127134.

Rogers, P. N. (1995). The general deterrent impact of California's $0.08 \%$ blood alcohol concentration limit and administrative per se license suspension laws. Sacramento: California Department of Motor Vehicles.

Ross, H. L. (1992). Are DWI sanctions effective? Alcohol, Drugs and Driving, 8(1), 61-69.

Tashima, H. N., \& Helander, C. J. (1998). 1998 annual report of the California DUI management information system. Sacramento: California Department of Motor Vehicles.

van Oldenbeek, G., \& Coppin, R. S. (1965). Driving under suspension and revocation: A study of suspended and revoked drivers classified as negligent operators. Sacramento: California Department of Motor Vehicles.

Voas, R. B., \& Tippetts, A. S. (1995). Evaluation of Washington and Oregon license plate sticker laws. 37th Annual Proceedings of the Association for the Advancement of Automotive Medicine. Chicago, IL: Association for the Advancement of Automotive Medicine.

Voas, R. B., Tippetts, A. S., \& Taylor, E. (1997). Temporary vehicle immobilization: Evaluation of a program in Ohio. Accident Analysis \& Prevention, 29(5), 635642.

Voas, R. B., Tippetts, A. S., \& Taylor, E. (1998). Temporary vehicle impoundment in Ohio: A replication and Confirmation. Accident Analysis \& Prevention, 30(5), 651-655.

Wells-Parker, E., Bangert-Drowns, R., McMillen, R., \& Williams, M. (1995). Final results from a meta-analysis of remedial interventions with drink/drive offenders. Addiction, 90, 907-926. 
DOT HS 809036

April 2000

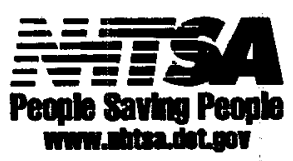

